\title{
In silico exploration of the mechanisms that underlie parasite-induced anorexia in sheep
}

\author{
Yan C. S. M. Laurenson ${ }^{1 *}$, Stephen C. Bishop ${ }^{1}$ and Ilias Kyriazakis ${ }^{2,3}$ \\ ${ }^{1}$ The Roslin Institute and Royal (Dick) School of Veterinary Studies, University of Edinburgh, Midlothian EH25 9RG, UK \\ ${ }^{2}$ School of Agriculture, Food and Rural Development, Newcastle University, Newcastle upon Tyne NE1 7RU, UK \\ ${ }^{3}$ Veterinary Faculty, University of Thessaly, PO Box 199, 43100 Karditsa, Greece \\ (Received 9 September 2010 - Revised 13 January 2011 - Accepted 17 February 2011 - First published online 20 April 2011)
}

\section{Abstract}

A model was used to investigate two mechanisms describing reductions in food intake (anorexia) observed during gastrointestinal parasitism in lambs, and to explore relationships between anorexia and food composition. The mechanisms were either a reduction in intrinsic growth rate, leading to a consequent reduction in food intake (mechanism 1; M1), or a direct reduction in food intake (mechanism 2; M2). For both mechanisms, lambs growing from 2 to 6 months of age were modelled, with one of three levels of trickle challenge with Teladorsagia circumcincta. Scenarios were simulated for feeds varying in either protein or energy content, or both. Major differences were found between the predictions resulting from M1 and M2 on low-energy foods that constrained the intake of uninfected lambs through bulk. With M1, food intake was governed by the first operating constraint, whereas with M2 an additivity of constraints was observed. On the other foods, the duration of anorexia increased with increasing energy content of feed for M1, whilst the duration of anorexia decreased with increasing protein content of feed for M2.For foods that did not have an impact upon lambs' gastrointestinal tract capacity, published data were consistent with predictions of M2. Due to an absence of experimental data, no conclusions could be drawn for relationships between anorexia and food composition in the presence of other limiting constraints, such as bulk for lowenergy foods. In conclusion, available experimental data and model predictions were consistent with anorexia having an impact directly on food intake, and with impacts of anorexia increasing with decreasing protein content.

\section{Key words: Lambs: Food composition: Modelling: Nematodes}

Gastrointestinal parasitism is one of the most pervasive challenges to the health and welfare of mammalian hosts. One of the main consequences of gastrointestinal parasitism is the occurrence of a reduction in voluntary food intake, henceforth called anorexia, which under subclinical infections accounts for up to a $20 \%$ reduction in the food intake of parasitised animals, compared with their non-infected counterparts $^{(1-3)}$. Clinical helminth infections, however, may lead to a complete cessation of eating ${ }^{(4-6)}$. Given the fact that gastrointestinal parasitism imposes nutritional penalties on the host $^{(7)}$, anorexia and its subsequent consequences are the major contributors to the impacts of parasitism on host performance and overall fitness. The effects on host performance can be large; for example, the economic cost of gastrointestinal parasitism of grazing sheep in the UK was estimated at about $£ 84$ million per year ${ }^{(8)}$. In the present paper we deal with the issue of anorexia during gastrointestinal parasitism in sheep because of its apparent economic significance and the consequent attention the phenomenon has received in these hosts. We are of the view, however, that the principles we develop will be relevant to other parasite-mammalian host systems.

There are both functional and causal hypotheses to account for the occurrence of anorexia during parasitism in most mammalian hosts, including sheep. For example, Kyriazakis et al. ${ }^{(9)}$ have suggested that anorexia develops in order to allow hosts to cope with the exposure to pathogens. Langhans ${ }^{(10)}$ and Plata-Salamán ${ }^{(11)}$, on the other hand, have suggested that anorexia is a consequence of the activation of the immune response by anorexinogenic cytokines, which are produced in response to infection. However, neither of these two groups of hypotheses is able to adequately account for or predict the extent of anorexia, nor do they provide a framework for predicting consequences on the food intake and performance of parasitised animals. Thus, this phenomenon continues to be paradoxical ${ }^{(9)}$.

Abbreviations: AFRC, Agricultural and Food Research Council; CP, crude protein; FEC, faecal egg count; $L I$, larval intake; ME, metabolisable energy; MP, metabolisable protein; PG, protein growth.

*Corresponding author: Mr Yan Laurenson, email yan.laurenson@roslin.ed.ac.uk 
There are at least two ways to account for the reduction in the food intake of growing animals during exposure to environmental and other stressors. Wellock et al. ${ }^{(12)}$ have suggested that the reduction in food intake is a consequence of a reduction in the intrinsic growth rate of the animals; the implication of this is that the reduction in food intake may be modelled as a consequence of reduction in growth (mechanism 1). This mechanism was implemented by Vagenas et $a l .{ }^{(13,14)}$ when modelling host-parasite interactions in growing lambs, and implies that animals' intrinsic growth capability changes, for example, in a manner akin to the gene expression alterations seen with fetal programming ${ }^{(15)}$. Sandberg et $a l^{(2)}$, on the other hand, have suggested that anorexia could be modelled as a direct reduction in the relative food intake of the parasitised animals (mechanism 2), which may be due to inappetence caused by immune response components such as cytokines. These authors have used this approach to model the time trend of food intake during the course of infection, mainly in pigs. A third approach has been proposed by Black et al. ${ }^{(16)}$ in which the above two mechanisms were used in equal proportion to account for the reduction in food intake. This approach is not considered any further in the present paper, due to it simply being a composite of the other two proposed mechanisms. To date, no attempt has been made to compare and consider the consequences of the above mechanisms on the extent of anorexia and its consequences on the performance of parasitised animals.

Further gaps exist in our understanding of the relationship between food composition and anorexia. For example, currently there is little known on whether and how food composition affects the characteristics of anorexia, such as its extent, duration and impact on animal performance. A recent paper by Kyriazakis ${ }^{(17)}$ reviewed extensively the literature on this issue and concluded that there was a significant lack of experimental evidence that would allow us to reach unequivocal conclusions about this relationship, and use it to the advantage of parasitised hosts. One issue that was specifically identified by the review was the lack of evidence on the nature of parasite-induced anorexia on low-quality foods, irrespective of whether such foods were low in N or energy.

The aim of the present paper was to investigate, in silico, the consequences of the above two mechanisms on the food intake of parasitised sheep. Parasitism was through infection with Teladorsagia circumcincta, which is the most prevalent parasite of sheep in temperate climates ${ }^{(18)}$. We used the model of Vagenas et al. ${ }^{(13,14)}$ as our starting point, as it is capable of accounting for the interaction between nutrition and gastrointestinal parasitism for growing and immunologically naive sheep. Several modifications were made to the model, which are described below, to alter both the cause and the mechanism of impact of anorexia. To model the consequences of $T$. circumcinta infection, anorexia was parameterised as a function of immune responses, rather than the worm mass parameterisation used by Vagenas et al. ${ }^{(13)}$. Further, the model was altered to allow for the investigation of the two proposed mechanisms by which anorexia leads to reduced food intake. The outcomes of this exercise were compared with existing data on the food intake of parasitised sheep in order to provide insights into the nature of anorexia during gastrointestinal parasitism in sheep and its likely impacts on host performance. In addition, we investigated the relationship between anorexia and food composition. Our hypothesis was that we would observe interactions between food composition and mechanism of anorexia, in terms of the observed anorexia, total food intake and level of parasitism. The outcomes of this exercise were expected to have heuristic value, giving insight into the design of future experiments that wish to address this issue.

\section{Materials and methods}

\section{Host-parasite interaction model}

A previously developed model ${ }^{(13)}$ that describes the impact of host nutrition, genotype and gastrointestinal parasitism in a growing lamb was modified and used to explore two mechanisms to account for parasite-induced anorexia. A schematic diagram describing the structure of the model is provided in Fig. 1. A description of each component of the model is given below. Equations and relationships previously published are given in the corresponding sections of Appendix 1, whereas modifications to the model remain in the main body of the text. First, the model for daily growth of an unchallenged animal is described for both non-limiting and nutritionally limiting conditions; the model is then extended to accommodate parasitic challenges, host immunity and host-parasite interactions, and to predict the growth of the lamb and its parasitic burden over time.

\section{The parasite-free animal}

Intrinsic growth model. The growing lamb is described by the initial fleece-free empty body weight (body weight minus gut fill and wool) and the expected protein and lipid body content at maturity ( $P_{\mathrm{m}}$ and $L_{\mathrm{m}}$, respectively). The intrinsic growth rate of the lamb $(B ; \mathrm{kg} / \mathrm{d})$ is given as equation 1 in Appendix 1.

The fleece-free empty body is considered to be the sum of the body protein, ash, water and lipid, and it is assumed that the lamb aims to achieve its expected intrinsic growth for these components. The desired maximum daily protein growth $\left(\Delta P G_{\max } ; \mathrm{kg} / \mathrm{d}\right)$, desired daily lipid growth $\left(\Delta L_{\mathrm{des}}\right.$; $\mathrm{kg} / \mathrm{d})$, daily accretion of ash $(\Delta A s h ; \mathrm{kg} / \mathrm{d})$ and daily accretion of water $(\Delta$ Water $; \mathrm{kg} / \mathrm{d})$ are given as equations $2,3,4$ and 5 , respectively, in Appendix 1.

The live weight of the lamb is given by the fleece-free empty body weight plus wool and gut fill. The expected maximum daily wool growth $\left(\Delta P W o o l_{\text {max }} ; \mathrm{kg} / \mathrm{d}\right)$ and gut fill $(G F ; \mathrm{kg})$ are given as equations 6 and 7 in Appendix 1.

Resource requirements and food intake. The protein and energy requirements to fulfil the expected growth rates are subsequently estimated. Only the protein and energy requirements have been considered ${ }^{(19)}$, as all other nutrient requirements are assumed to be satisfied by the diet. The daily protein requirements for maintenance, growth and wool are 


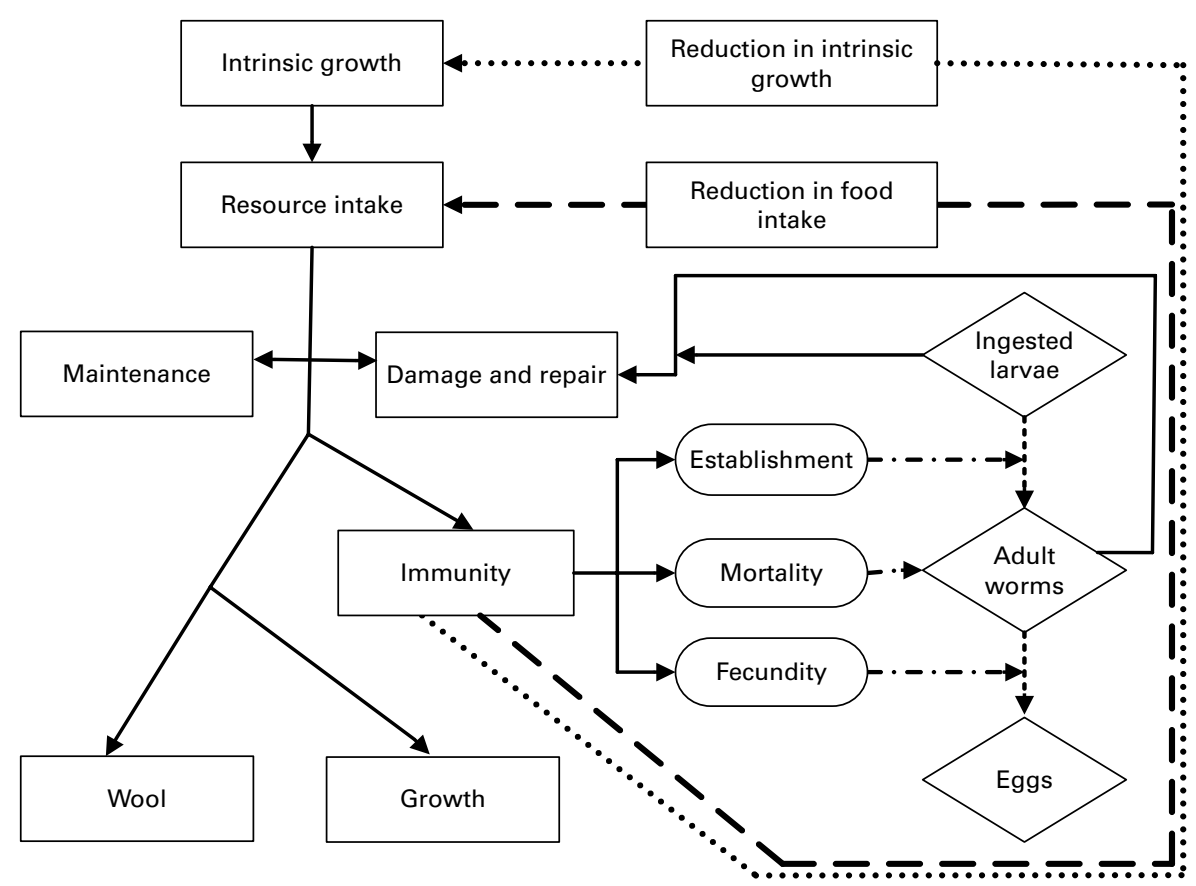

Fig. 1. Schematic description of host-parasite interactions and parasite-induced anorexia mechanisms (mechanism 1: intrinsic growth reduction mechanism (.-...); mechanism 2: food intake reduction mechanism (-- -)) in sheep infected with gastrointestinal nematodes. Rectangular boxes indicate the flow of food resources (for descriptions of the components, see the Methods section). Rounded boxes indicate host-parasite interactions and diamond boxes indicate key quantifiable parasite lifecycle stages.

estimated by equations 8, 9 and 10 in Appendix 1. Energy requirements are estimated assuming that the deposition of wool protein has the same energy requirement per unit mass as body protein ${ }^{(20)}$. The daily energy requirements for maintenance, growth and wool are estimated by equations 11, 12 and 13 in Appendix 1. Total protein requirements $(P R)$ and total energy requirements $(E R)$ are simply the sum of the individual requirements for maintenance, growth and wool.

It is assumed that the lamb will attempt to ingest sufficient nutrients to meet its expected requirements for growth. The desired feed intake is therefore the feed intake necessary to meet the expected requirements. Desired food intake for meeting, separately, the energy $\left(F I_{\mathrm{E}}\right)$ and protein $\left(F I_{\mathrm{P}}\right)$ requirements of the lamb are estimated by equations 14 and 15 in Appendix 1. The desired food intake of the animal is calculated as the higher of $F I_{\mathrm{E}}$ and $F I_{\mathrm{P}}$. The energy requirements of the lamb were expressed in terms of effective energy (EE) $(\mathrm{MJ} / \mathrm{kg})$ in accordance with Emmans ${ }^{(21)}$. These $E E$ requirements were linked to the metabolisable energy $(M E)$ $(\mathrm{MJ} / \mathrm{kg})$ yielded by a feed using equation 16 in Appendix 1.

Constrained resources. Under many circumstances resources may be constrained or insufficient to meet requirements. The procedure described above results in a food intake that increases as the quality (protein and energy content) of the feed decreases. However, it has been observed that the rate of increase in daily food intake declines as feed quality declines, and daily food intake may decrease for feeds with a low energy content ${ }^{(22)}$ due to an assumed maximum capacity for bulk. To represent this, a quantity called constrained food intake $(C F I)$ is defined by equation
17 in Appendix 1. This relationship implies that the capacity of the animal for daily indigestible organic matter $(C A P ; \mathrm{kg})$ and the energy content of the food jointly determine the constrained food intake. $C A P$ in young lambs has been found to increase linearly, equal to proportionally 0.0223 of the current body weight up to 0.51 of mature body weight, and to remain constant thereafter ${ }^{(23)}$. Thus, $C A P$ is given by equation 18 in Appendix 1.

Actual food intake is then the lower of desired food intake and CFI. Efficiency of digestion, accounting for level of feeding $(L F)$, rumen outflow rate and current state of the lamb, and hence metabolisable protein (MP) available to the animal, were calculated using the equations described by the Agricultural and Food Research Council (AFRC) ${ }^{(20)}$.

Allocation of nutrients. Ingested protein and energy are allocated to various bodily functions. The maintenance needs of the lamb are assumed to be satisfied first and remaining nutrients are allocated to production (body protein, body lipid and wool growth). The energy remaining after allocation to maintenance and production is subsequently stored as additional lipid. The daily lipid deposited ( $\Delta$ Lipid) is given by equation 19 in Appendix 1 . If $\Delta$ Lipid is negative, then lipid will be catabolised to satisfy the animal's energetic needs for other functions as given by equation 20 in Appendix 1.

If the lamb has a MP intake that is below its maintenance requirements, it is assumed to use its body reserves to cover its maintenance functions. If this protein inadequacy is prolonged the lamb will catabolise body protein, eventually leading to death. The quantity of protein that the animal can 
mobilise from its body, i.e. labile protein $\left(P_{\text {Labile }}\right)^{(24,25)}$, is defined by equation 21 in Appendix 1.

The baseline body lipid level ( $L_{\mathrm{base}}$ ), i.e. the minimum body lipid content for animal survival, is estimated as a proportion of its body protein content $(P)$ as given by equation 22 in Appendix 1. If the energy intake of the lamb is not sufficient to meet this baseline body lipid level, then energy allocated towards protein growth is retracted and reallocated to lipid accretion. This scenario, which was absent from our previous model, is modelled by first calculating the required protein reduction $\left(P R_{\text {Red }}\right)$ that would be sufficient to fulfil the $L_{\text {base }}$ energy requirement. This is estimated as:

$$
P R_{\text {Red }}=\frac{\left(\left(\frac{b l}{b p}\right) \cdot\left(\left(L_{\text {base }} \cdot P\right)-L\right)\right)}{\left(\left(L_{\text {base }} \cdot\left(\frac{b l}{b p}\right)\right)+1\right)}(\mathrm{kg}),
$$

where $P=$ current body protein $(\mathrm{kg}), L=$ current body lipid (kg), $b l=$ energetic cost per $\mathrm{kg}$ of lipid deposition $(56 \mathrm{MJ} /$ $\mathrm{kg})^{(21)}$ and $b p=$ energetic cost per $\mathrm{kg}$ of protein deposition $(50 \mathrm{MJ} / \mathrm{kg})^{(21)}$.

The energy lipid shortfall $\left(E_{\mathrm{LS}}\right)$ is therefore calculated as:

$$
E_{\mathrm{LS}}=P R_{\mathrm{Red}} \cdot b p(\mathrm{MJ}) \text {. }
$$

Subsequently, daily protein $(\Delta P)$ and daily lipid $(\Delta L)$ deposited are given as:

$$
\begin{gathered}
\Delta P=\Delta P G-P R_{\mathrm{Red}}(\mathrm{kg}), \\
\Delta L=\Delta \text { Lipid }+\left(\frac{E_{\mathrm{LS}}}{b l}\right)(\mathrm{kg}),
\end{gathered}
$$

where $\triangle P G=$ protein growth $(\mathrm{kg})$.

\section{The parasitised animal}

Protein loss. Parasitism leads to protein loss in animals through damage to the gastrointestinal tract by ingested larvae and adult worms that develop from such larvae. Ingested larvae have a cost to the host manifested by protein loss, for example, tissue loss or plasma loss ${ }^{(24)}$. The potential protein loss $\left(P L I_{\mathrm{Pot}}\right)$ due to larval intake $(L I)$ when there is no immune response is given by equation 23 in Appendix 1 .

The animal is able to reduce the damage caused by $L I$ through its immune response. Thus in the presence of an immune response the protein loss due to $L I(P L I)$ is assumed to decrease. Actual protein loss due to $L I$ is therefore given by equation 24 in Appendix 1.

A proportion of the ingested larvae $(L I)$ will establish in the host gastrointestinal tract and develop to adult worms (see below). The adult worms will also cause protein loss to the host, for example, via damaged tissue or reduced absorption. However, the total number of adult worms present in the gastrointestinal tract (worm burden; WB) does not provide a complete description of the parasitic burden of the lamb $b^{(26)}$, because this does not take into account the mass of the adult worm burden or the effects of population density. To fully account for this, it is necessary to account for the total mass of the worm burden. Worm length has been shown to be strongly positively correlated with the fecundity $(F)$ of the worm (number of eggs produced) ${ }^{(27)}$. Further, it is assumed that worm length is closely related to, and hence may be used as a proxy for, worm mass. Therefore, the worm mass (WM) of a population of worms can be approximated as:

$$
W M \approx F \cdot W B .
$$

To take into account the density-dependence effects upon the worm population, in which individual worm size and fecundity decrease with increasing worm burden, fecundity was scaled as an inverse function of worm burden, assuming a mean worm burden of 2500. Thus, fecundity was scaled as given by equation 26 in Appendix 1, and worm mass given by equation 27 in Appendix 1.

The protein loss caused by worm mass $(P W M)$ is given by equation 28 in Appendix 1. Total protein loss (PLOSS) due to parasitism is therefore estimated as the sum of protein loss due to $L I(P L I)$ and protein loss caused by worm mass (PWM).

\section{Immune response}

The lamb is assumed to invest in the immune response in order to reduce the impact of parasitism. Lambs are initially naive to parasites and they develop immunity as a function of their exposure to infective larvae. The immune response is represented by the host-controlled traits of nematode establishment $(\varepsilon)$, fecundity $(F)$ and mortality $(\mu)$. The functions used to describe these three immune response traits, modified from those described by Louie et al. ${ }^{(28)}$ and Vagenas et al. ${ }^{(13)}$, are given by the following sigmoidal relationships:

$$
\varepsilon=\left(\frac{\varepsilon_{\max } \cdot K_{\varepsilon}^{3}}{K_{\varepsilon}^{3}+\left(\sum_{t} L I^{*}\right)^{3}}\right)+\varepsilon_{\min }
$$

(proportion of larvae establishing),

$$
\mu=\left(\frac{\mu_{\max } \cdot\left(\sum_{t} L I^{*}\right)^{3}}{m i^{3}+\left(\sum_{t} L I^{*}\right)^{3}}\right)+\mu_{\min }
$$

(proportion of adult worms/d),

$$
F=\left(\frac{F_{\max } f i^{3}}{f i^{3}+\left(\sum_{t} L I^{*}\right)^{3}}\right)+F_{\min } \quad(\text { eggs/worm } / \mathrm{d})
$$

where $\varepsilon_{\max }, \mu_{\max }$ and $F_{\max }=$ maximum establishment $\left(0 \cdot 7^{(29)}\right)$, mortality $\left(0 \cdot 11^{(29)}\right)$ and fecundity $\left(20^{(26)}\right)$ rates, respectively, $\varepsilon_{\mathrm{min}}, \quad \mu_{\mathrm{min}}$ and $F_{\min }=$ minimum establishment $\left(0.06^{(29)}\right)$, mortality $\left(0 \cdot 01^{(30)}\right)$ and fecundity $\left(5^{(13,14)}\right)$ rates, respectively, 
$\sum L I^{*}=$ scaled cumulative $L I$ (see below), and $K_{\varepsilon}, m i$ and

$f i=$ rate constants for establishment (200 000), mortality (450

000) and fecundity (230 000), respectively.

Scaled cumulative LI $\left(\sum_{t} L I^{*}\right)$ is given as:

$$
\sum_{t} L I^{*}=\sum_{t-1} L I^{*}+\left(\left(L I_{\max } \cdot \frac{L I}{L I+c l i}\right) \cdot\left(\frac{P A C_{\mathrm{Imm}}}{\left(P R Q_{\mathrm{Imm}}\right)_{\mathrm{Tot}}}\right)\right),
$$

where $c l i=$ constant of relationship between $\sum_{t} L I^{*}$ and $\sum_{t-1} L I^{*}\left(2000^{(13)}\right)$.

${ }^{t-1}$ The immune response is assumed to be predominantly driven by protein; as such, the protein requirements for immunity are calculated separately for $L I$ and worm mass (WM) and are given as equations 29 and 30 in Appendix 1. Thus the total protein required for immunity $\left(\left(P R Q_{\text {Imm }}\right)_{\text {Tot }}\right)$ is given by the sum of requirements for $L I$ and worm mass.

Effect of parasitism on protein partitioning. As in the case of no parasitic challenge, it is assumed that the maintenance needs of the lamb will be satisfied first. If the available protein is less than the requirements for maintenance then the lamb must catabolise protein. In this case, no protein is allocated to immunity or production. Otherwise, nutrients remaining after allocation to maintenance are allocated to immunity and production (body and wool growth) in proportion to their requirements. Protein allocated to production $\left(\mathrm{PAC}_{\mathrm{Growth}}\right)$ and protein allocated to immunity $\left(\mathrm{PAC}_{\mathrm{Imm}}\right)$ are given by equations 31 and 32 in Appendix 1. This approach is different from the traditional view of considering the requirements for the immune response as part of the maintenance requirements ${ }^{(31)}$. Metabolised protein allocated to immunity is assumed to be used with an efficiency of $0.59^{(20)}$; thus the quantity of protein associated with the immune function per $\mathrm{d}$ is given by equation 33 in Appendix 1 .

Due to protein being allocated to immunity there will be a reduction in protein loss due to parasitism. Protein loss due to worm mass is then re-estimated after the reduction in fecundity and recalculating worm mass, and the protein loss spared added back to the available protein $\left(P_{\text {Avail }}\right)$. Subsequently the final protein allocated to production $\left(P A C_{\text {Prod }}^{\mathrm{F}}\right)$ is estimated as:

$$
P A C_{\text {Prod }}^{\mathrm{F}}=P_{\text {Avail }}-\left(P A C_{\mathrm{Imm}}+P L O S s\right)(\mathrm{kg} / \mathrm{d}) .
$$

Effect of parasitism on food intake. In the model of Vagenas et al. ${ }^{(13)}$, anorexia was assumed to be a function of adult worm burden; however, this mechanism leads to anorexia commencing too late (i.e. after $21 \mathrm{~d}$ post-infection) for T. circumcincta; Coop et al. ${ }^{(1)}$ and Greer et al. ${ }^{(32)}$ reported that anorexia became apparent 7-10 d after initial challenge with $T$. circumcincta. Because immune response components such as cytokines cause inappetance, we modelled anorexia as a direct function of the rate of acquisition of immunity as this formulation captures the time-dependent dynamics of T. circumcincta-induced anorexia. Anorexia was then applied to either the intrinsic growth rate or actual food intake, as described below, through a reduction parameter $(R E D)$. $R E D$ is calculated as a direct function of the rates (i.e. 1st derivatives) of immune response acquisition as:

$$
R E D=R_{\mathrm{c}} \cdot\left(\frac{d \varepsilon}{d x}+\frac{d \mu}{d x}+\frac{d F}{d x}\right)
$$

where $R_{\mathrm{C}}=$ constant linking the reduction to the immune response, $\varepsilon=$ establishment, $F=$ fecundity and $\mu=$ mortality. During the course of an infection $R E D$ will start at zero, rise to a maximum and then decline towards zero as immunity is fully acquired.

Anorexia was then implemented through the two mechanisms as follows.

Mechanism 1: The reduction was applied to the intrinsic growth rate; thus the reduction in food intake may be modelled as a consequence of a reduction in growth. In order to represent the reduction in intrinsic growth the reduction calculated above is implemented as ${ }^{(13)}$ :

$$
B_{\mathrm{New}}=B \cdot R E D,
$$

where $B_{\text {New }}=$ new rate of tissue mass retention.

Mechanism 2: The reduction equation was applied directly to the food intake $(F I)$ of the lamb to obtain:

$$
F I_{\text {New }}=F I \cdot R E D .
$$

$F I_{\text {New }}$ therefore gives the food intake of the lamb as a consequence of parasite-induced anorexia.

\section{Experimental design}

The model was used to explore the consequences of the two different mechanisms for parasite-induced anorexia. For both mechanisms, the model was used to investigate the effect of nutrition and varying levels of challenge with T. circumcincta on the performance of a lamb growing from 2 to 6 months of age. This time period was chosen to represent the period in which the lambs are growing at their maximum rate whilst not being fully immune, and thus the period in which parasitism can be expected to have its greatest impact upon weight gain. The model predicts events for time increments of $1 \mathrm{~d}$ and it was updated on a daily basis, with predictions from the previous day being used as the starting point for the current day.

The lambs were simulated to have an initial live weight of about $20 \mathrm{~kg}$ corresponding to an initial empty body weight of $12.73 \mathrm{~kg}$ and an initial body protein weight of $2.03 \mathrm{~kg}$. The genotype traits of the lamb were a protein weight at maturity $\left(P_{m}\right)$ of $9.525 \mathrm{~kg}$, a lipid weight at maturity $\left(L_{m}\right)$ of $40 \cdot 11 \mathrm{~kg}$ and a growth rate parameter $(B)$ of $0 \cdot 0125$. These parameter values were chosen to give growth characteristics similar to those of Scottish Blackface lambs, a common British breed.

For both mechanisms of parasite-induced anorexia, lambs were given a trickle challenge infection of $T$. circumcincta $\mathrm{L}_{3}$ larvae of either control, 1000 or $5000 \mathrm{~L}_{3}$ per $\mathrm{d}$, from day 1 . Numerous levels of larval challenge were initially investigated; the $5000 \mathrm{~L}_{3}$ per $\mathrm{d}$ challenge is reported here as it corresponds to the high level of subclinical $T$. circumcincta infections investigated by Coop et al. ${ }^{(33)}$, which lead to parasite-induced anorexia and reduced growth rate. The $1000 \mathrm{~L}_{3}$ per $\mathrm{d}$ 
Table 1. Composition of the foods used in the experiments*

\begin{tabular}{|c|c|c|c|c|c|c|c|c|}
\hline \multirow[b]{2}{*}{ LF } & \multirow[b]{2}{*}{ Description } & \multicolumn{7}{|c|}{ Feed } \\
\hline & & 1 & 2 & 3 & 4 & 5 & 6 & 7 \\
\hline & CP (g/kg DM) & 90 & 115 & 140 & 140 & 140 & 165 & 190 \\
\hline & ME (MJ/kg DM) & $7 \cdot 50$ & $10 \cdot 0$ & 8.75 & $10 \cdot 0$ & $11 \cdot 25$ & $10 \cdot 0$ & $12 \cdot 5$ \\
\hline & FME (MJ/kg DM) & 6.45 & 8.95 & $7 \cdot 70$ & 8.95 & $10 \cdot 2$ & 8.95 & 11.45 \\
\hline \multirow[t]{5}{*}{6} & $\mathrm{RP}(\mathrm{g} / \mathrm{kg} \mathrm{DM})$ & $31 \cdot 2$ & 56 & $67 \cdot 1$ & $72 \cdot 1$ & $80 \cdot 4$ & 88.2 & $100 \cdot 7$ \\
\hline & UP (g/kg DM) & $56 \cdot 1$ & $52 \cdot 1$ & 65.0 & $59 \cdot 3$ & $50 \cdot 3$ & 67.9 & 84.7 \\
\hline & DUP (g/kg DM) & $46 \cdot 6$ & $42 \cdot 7$ & $52 \cdot 2$ & 47.9 & $40 \cdot 1$ & $55 \cdot 8$ & $70 \cdot 1$ \\
\hline & MP (MJ/kg DM) & $66 \cdot 4$ & $78 \cdot 4$ & 95.0 & 93.8 & 91.4 & 112 & $134 \cdot 3$ \\
\hline & MP:ME & 8.85 & $7 \cdot 84$ & $10 \cdot 86$ & $9 \cdot 38$ & 8.12 & $11 \cdot 2$ & $10 \cdot 74$ \\
\hline
\end{tabular}

LF, level of feeding as multiples of energy requirements for maintenance; CP, crude protein; ME, metabolisable energy; FME, fermentable metabolisable energy; RP, rumen degradable protein; UP, undegradable protein; DUP, digestible undegradable protein; MP, metabolisable protein; AFRC, Agricultural and Food Research Council.

* The composition of foods 1,4 and 7 were taken from appendix 1 of the recommendations of the AFRC ${ }^{(20)}$ as examples of poor-, medium- and good-quality grass, respectively. For foods 2,4 and 6 the CP content of the food was varied systematically whilst keeping ME content constant, and for foods 3,4 and 5 the ME content was varied systematically whilst the CP content remained constant.

challenge was chosen to represent a lower challenge level as used by Valderrábano et al. ${ }^{(34)}$ and Coop et $a l^{(1)}$, and for comparison with the previously published model of Vagenas et $a{ }^{(13,14)}$. This level of infection also has consequences on the food intake predicted by the two different mechanisms and therefore has a heuristic value.

This scenario was simulated for each of seven different grass qualities (Table 1; Fig. 2). Foods 1, 4 and 7 were taken from appendix 1 of the $\mathrm{AFRC}^{(20)}$ manual as being representative of poor-, medium- and good-quality grasses; they were equally spaced in terms of energy and $\mathrm{N}$ contents. Foods 1 and 7 have been previously used in the same model ${ }^{(13,14,35)}$ to investigate the impact of food composition on the extent of parasitism in growing lambs. Four additional 'grasses' (foods 2, 3, 5 and 6) were also used for the purposes of the simulations; their composition was considered appropriate and within realistic bounds to investigate the impact of food energy or protein content alone on anorexia during parasitism. Foods 2 and 6 were isoenergetic in terms of ME to grass 4 (10 MJ ME/kg DM), but contained $\mathrm{N}$ levels that were placed between foods 1, 4 and 7, whereas foods 3 and 5 were isonitrogenous in terms of crude protein (CP) to grass $4(140 \mathrm{~g} \mathrm{CP} / \mathrm{kg} \mathrm{DM})$, but contained ME levels that were placed between the same foods. The composition of foods 2, 3, 5 and 7 was also estimated in accordance with AFRC recommendations ${ }^{(20)}$. All foods were assumed to have the same ash content $(70 \mathrm{~g} / \mathrm{kg} \mathrm{DM})$ and the same fat content $\left(30 \mathrm{~g} / \mathrm{kg} \mathrm{DM}{ }^{(36)}\right)$. For the calculation of the MP content of the foods, the assumptions made regarding the impact of the feeding level in relation to maintenance were adjusted as the animals grew, but the yields of protein given in Table 1 are for a level of feeding of six times maintenance.

The outputs from the model are presented for food intake ( $\mathrm{kg} / \mathrm{d})$ and daily worm egg count (eggs/d). The food intake was reported in order to present the differences that occur for the two mechanisms of parasite-induced anorexia. The live-weight predictions are not presented here, as they are a direct consequence of the food intake of the lamb. The daily worm egg count, which is the total number of eggs produced per d, was chosen to present the parasitological outcomes of our predictions. This was preferred over faecal egg count
(FEC), which is the number of eggs per $\mathrm{g}$ faeces, in order to overcome the dilution effect of the quantity of faeces produced upon the parasitological predictions.

\section{Model validation}

The model was parameterised using the results of Coop et $a l .{ }^{(1)}$. However, to ensure that the values predicted by the model were representative of values reported in experiments other than Coop et al. ${ }^{(1)}$, a search was carried out for published comparable experiments. Experiments investigating the impacts of $T$. circumcinta infection on growing lambs were checked against selected criteria. These criteria were: sufficient information on food composition, ad libitum feeding and the use of non-parasitised control animals. Two experiments met these criteria and contained sufficient information to enable simulations to be carried out for comparison; these were experiments described by Greer et al $^{(32)}$ and Valderrábano et al. ${ }^{(34)}$

Greer et al. ${ }^{(32)}$ infected immunologically naive Coopworth ewe lambs with either control or $4000 T$. circumcincta $\mathrm{L}_{3}$ per $\mathrm{d}$ for 9 weeks, and offered them ad libitum access to

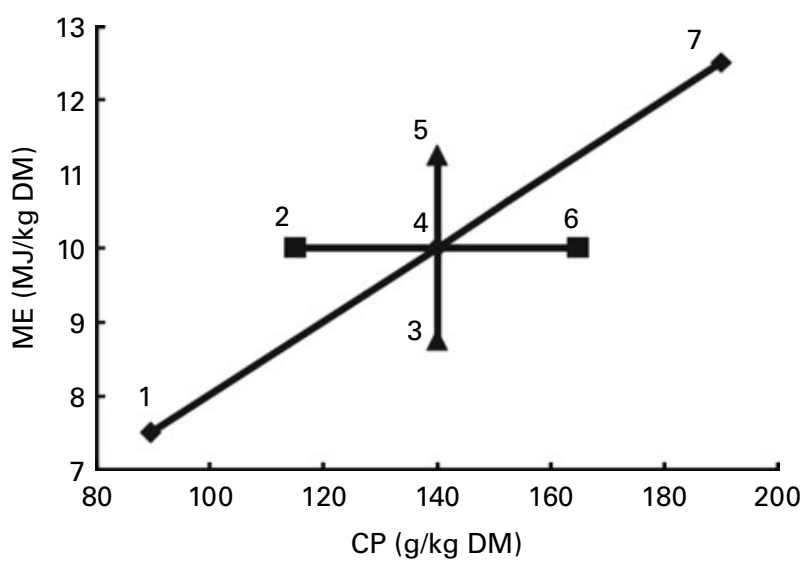

Fig. 2. Nutritional space occupied by the foods used in the simulated experiments. Foods 2, 4 and 6 differed in their crude protein (CP) contents, foods 3,4 and 5 differed in their metabolisable energy (ME) contents and foods 1 , 4 and 7 differed in both their CP and ME contents. 
food containing $10.5 \mathrm{MJ} \mathrm{ME} / \mathrm{kg} \mathrm{DM}$ and $146 \mathrm{~g}$ crude protein (CP) $/ \mathrm{kg}$ DM. Coopworth lambs were assumed to be similar in terms of their growth characteristics to the sheep used for our simulations.

Valderrábano et $a l .{ }^{(34)}$ infected immunologically naive Rasa Aragonesa female lambs with either 0 or 1000 T. circumcincta $\mathrm{L}_{3}$ per $\mathrm{d}$ for 6 weeks, and offered ad libitum access to food containing $13.25 \mathrm{MJ} \mathrm{ME} / \mathrm{kg} \mathrm{DM}$ and $175.5 \mathrm{~g} \mathrm{CP} / \mathrm{kg} \mathrm{DM}$. Genetic descriptions of Rasa Aragonesa lambs in the terms required by our model do not appear to exist in the literature. For this reason the model was calibrated for the growth rates and food intake of the non-infected sheep; thus the performance and food intake of the infected sheep were model predictions.

\section{Results}

\section{Validation}

The model predictions for anorexia and FEC were close to those reported by Greer et al. ${ }^{(32)}$; however, impacts of parasitism on growth rate were under-predicted. The model predicted a reduction in the food intake of infected lambs of $0 \cdot 16$ from 15 to $28 \mathrm{~d}$ post-infection in comparison with uninfected lambs; this is similar to the reported $0 \cdot 17$ reduction in the intake of the infected lambs over the same time period. Infected lambs were predicted to have a $26 \%$ slower growth rate than uninfected lambs until day 38 post-infection, after which growth rates became similar. Infected lambs were predicted to remain proportionately 0.09 lighter than control lambs at $63 \mathrm{~d}$ post-infection. The reported growth rate for infected sheep was $43 \%$ lower than that of uninfected sheep up to day 35 of infection and infected lambs were proportionately $0 \cdot 11$ lighter at $63 \mathrm{~d}$ post-infection. FEC was predicted to peak $30 \mathrm{~d}$ post-infection, and the observed FEC peak occurred $28 \mathrm{~d}$ post-infection.

Simulations reproducing the experiment of Valderrábano et $a l .{ }^{(34)}$ predicted an average food intake of $1060 \mathrm{~g} / \mathrm{d}$ for infected and $999 \mathrm{~g} / \mathrm{d}$ for infected sheep, showing a $6 \%$ reduction in the average food intake of infected lambs in comparison with their uninfected counterparts over the experimental period. These compare favourably with the reported intakes of 1070 and $960 \mathrm{~g} / \mathrm{d}$, respectively, although the observed reduction in the average food intake of infected lambs was slightly higher (10\%). Some of this difference could be due to the assumptions made to convert the reported $\mathrm{CP}$ content of the feed to MP.

\section{Food intake}

The daily food intakes for uninfected lambs are shown in Fig. 3 for foods differing in both energy and protein content (a), for the three isoenergetic foods (b) and for the three isonitrogenous foods (c). Figure 4 shows the food intake for lambs challenged with control, 1000 or 5000 larvae per d offered access to either food 4 for mechanism 1 (Fig. 1(a)) and for mechanism 2 (Fig. 1(b)) or food 1 for mechanism 1 (Fig. 1(c)) and for mechanism 2 (Fig. 1(d)). Average food intake predictions for

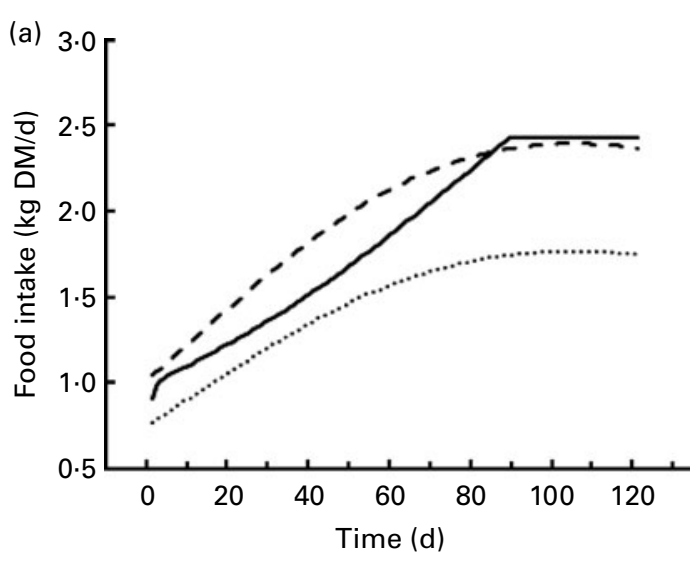

(b)
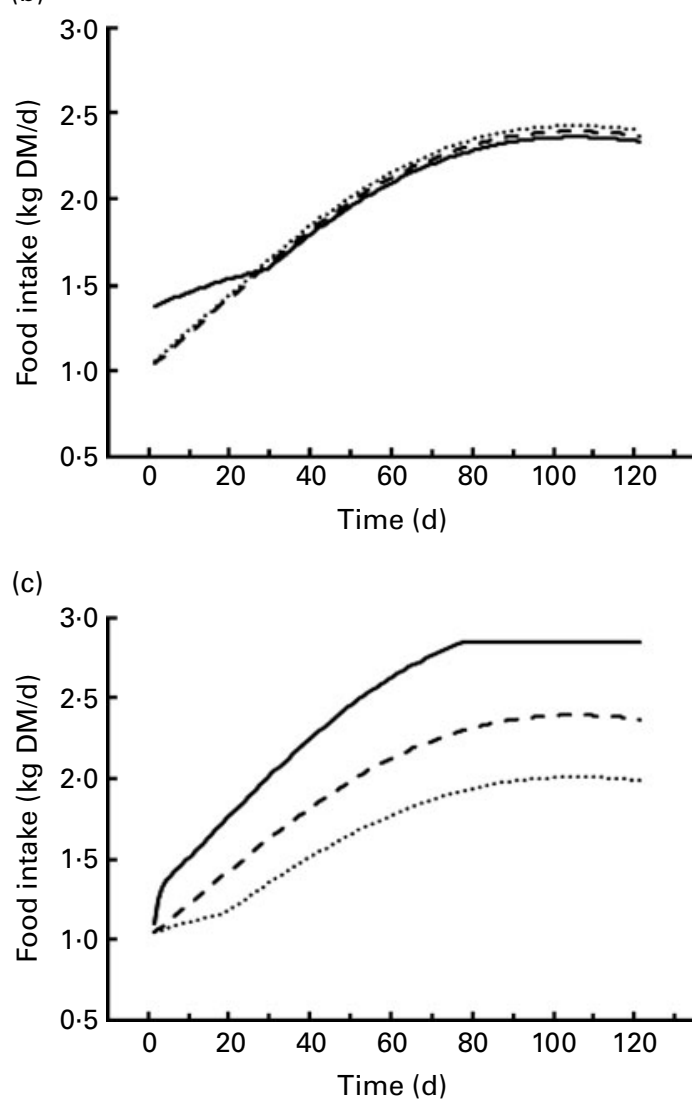

Fig. 3. Food intake predictions for uninfected lambs given ad libitum access to foods of different crude protein (CP) and metabolisable energy (ME) content (for details of foods, see Table 1). (a) Foods of different CP and ME contents $(-$, Food $1 ;-\cdots$, food $4 ; \cdots \cdots$, food 7 ). (b) Foods of different CP content but the same ME content (10 MJ/kg DM) (—, Food 2; - . -, food 4; ......, food 6). (c) Foods of different ME content but the same CP content $(140 \mathrm{~g} / \mathrm{kg} \mathrm{DM})(-$, Food $3 ;---$, food $4 ; \cdots \cdots$. , food 5$)$.

uninfected lambs, and the relative food intake of lambs challenged with 1000 or 5000 larvae per d (given as a proportion of uninfected lambs) for both anorexia mechanisms and for all foods are summarised in Table 2. The maximum extent of anorexia (largest reduction predicted in comparison with uninfected lambs), including the day at which the maximum extent was observed, and the duration of anorexia are summarised in Table 3. Duration was defined as the number 

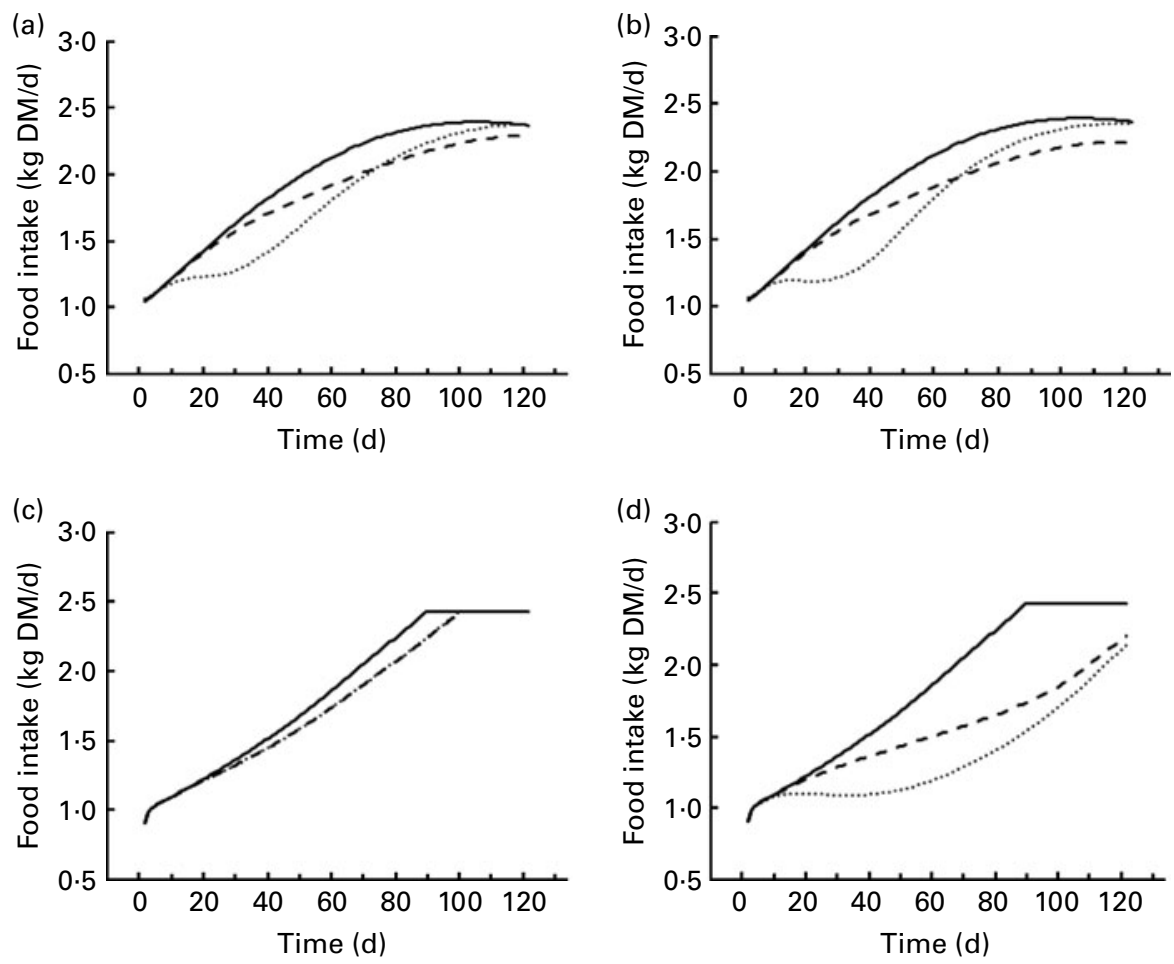

Fig. 4. (a) Food intake predictions for mechanism 1 (reduction in the intrinsic capacity for growth) for lambs given access to food 4 (crude protein $=140 \mathrm{~g} / \mathrm{kg} \mathrm{DM}$; metabolisable energy $=10 \mathrm{MJ} / \mathrm{kg} \mathrm{DM}$ ), whilst exposed to control (-), 1000 (- - -) or 5000 (......) Teladorsagia circumcincta $\mathrm{L}_{3}$ per d. (b) Food intake predictions for mechanism 2 (direct reduction in food intake) for lambs given access to food 4. (c) Food intake predictions for mechanism 1 for lambs given access to food 1 (crude protein $=90 \mathrm{~g} / \mathrm{kg}$ DM; metabolisable energy $=7.5 \mathrm{MJ} / \mathrm{kg} \mathrm{DM}$ ). (d) Food intake predictions for mechanism 2 for lambs given access to food 1.

of days during which the proportional reduction in food intake was greater than $0 \cdot 05$.

Across all foods investigated, with the exception of the food low in both protein and energy (food 1), food intake for infected lambs presented similar patterns for both mechanisms of anorexia, differing only in the predicted the duration and extent of anorexia; the extent of anorexia was greater for larger levels of challenge. In general, mechanism 2 had a greater maximum extent of anorexia and lower relative food intake than mechanism 1 for both levels of challenge and for all foods. For mechanism 1 the duration of anorexia remained similar for both levels of infection, whilst for mechanism 2 for all foods the duration of anorexia was longer for lambs challenged with 1000 larvae per d than for lambs challenged with 5000 larvae per $\mathrm{d}$.

Comparisons between foods for both mechanisms are explored in more detail below.

Effect of nitrogen content on food intake (foods 2, 4 and 6). The effect of $\mathrm{N}$ content on food intake of uninfected lambs was small (Fig. 3(b)), with the exception of the food intake of the lambs on the lowest- $\mathrm{N}$ food during the early stages of growth (food 2). The model predicted that lambs offered access to food 2 would compensate for the food $\mathrm{N}$ content by increasing their food intake for the first $28 \mathrm{~d}$ of the simulated experiment, when this food was first limiting in MP.

For infected lambs, $\mathrm{N}$ content of the food had different impacts on relative food intake, and the maximum extent and duration of anorexia for the two mechanisms. Little effect of the $\mathrm{N}$ content of the food was seen on relative food intake, and the maximum extent and duration of anorexia for mechanism 1. However, for mechanism 2 the $\mathrm{N}$ content of the food affected the duration of anorexia for lambs challenged with 5000 larvae per d. The duration of anorexia decreased from 84 to $74 \mathrm{~d}$ as food CP content increased from 115 to $165 \mathrm{~g} / \mathrm{kg} \mathrm{DM}$, although the maximum extent of anorexia was not affected significantly by food $\mathrm{N}$ content, remaining at about 0.26 for all three foods. For lambs

Table 2. Average food intake $(\mathrm{kg})$ predictions for uninfected (control) lambs, and total relative food intake predictions for mechanisms 1 and 2 for lambs given access to foods of different crude protein and metabolisable energy content and exposed to 1000 or 5000 Teladorsagia circumcincta $\mathrm{L}_{3}$ per $\mathrm{d}$ over $121 \mathrm{~d}$

\begin{tabular}{|c|c|c|c|c|c|}
\hline \multirow[b]{3}{*}{ Food $^{*}$} & \multirow{3}{*}{$\begin{array}{l}\text { Average food } \\
\text { intake of } \\
\text { controls }(\mathrm{kg})\end{array}$} & \multicolumn{4}{|c|}{$\begin{array}{l}\text { Total relative food intake } † \\
\text { (proportion of control) }\end{array}$} \\
\hline & & \multicolumn{2}{|c|}{ Mechanism 1‡ } & \multicolumn{2}{|c|}{ Mechanism $2 \S$} \\
\hline & & $1000 \mathrm{~L}_{3}$ & $5000 \mathrm{~L}_{3}$ & $1000 \mathrm{~L}_{3}$ & $5000 \mathrm{~L}_{3}$ \\
\hline 1 & $1 \cdot 849$ & 0.96 & 0.96 & 0.83 & 0.73 \\
\hline 2 & 1.999 & 0.94 & 0.90 & 0.92 & 0.88 \\
\hline 3 & $2 \cdot 419$ & 0.95 & 0.91 & 0.92 & 0.87 \\
\hline 4 & 1.982 & 0.94 & 0.90 & 0.92 & 0.89 \\
\hline 5 & 1.670 & 0.93 & 0.89 & 0.91 & 0.87 \\
\hline 6 & $2 \cdot 010$ & 0.94 & 0.90 & 0.92 & 0.90 \\
\hline 7 & 1.462 & 0.94 & 0.90 & 0.92 & 0.90 \\
\hline
\end{tabular}

*For details of foods, see Table 1.

† Total food intake given as a proportion of that of uninfected lambs.

$\ddagger$ Reduction in the intrinsic capacity for growth.

$\S$ Direct reduction in food intake. 
Table 3. Maximum extent of anorexia and duration of anorexia predictions for mechanisms 1 and 2 for lambs given access to foods of different crude protein and metabolisable energy content and exposed to 1000 or 5000 Teladorsagia circumcincta $\mathrm{L}_{3}$ per d over $121 \mathrm{~d}$

\begin{tabular}{|c|c|c|c|c|c|c|c|c|c|c|c|c|}
\hline \multirow[b]{4}{*}{ Food $^{*}$} & \multicolumn{8}{|c|}{ Maximum extent of anorexia } & & & & \\
\hline & \multicolumn{4}{|c|}{ Mechanism 1† } & \multicolumn{4}{|c|}{ Mechanism $2 \ddagger$} & \multicolumn{4}{|c|}{ Duration of anorexia $(d) \S$} \\
\hline & \multicolumn{2}{|c|}{$1000 L_{3}$} & \multicolumn{2}{|c|}{$5000 \mathrm{~L}_{3}$} & \multicolumn{2}{|c|}{$1000 L_{3}$} & \multicolumn{2}{|c|}{$5000 \mathrm{~L}_{3}$} & \multicolumn{2}{|c|}{ Mechanism 1† } & \multicolumn{2}{|c|}{ Mechanism 2‡ } \\
\hline & LRP & $\begin{array}{c}\text { Day of } \\
\text { maximum }\end{array}$ & LRP & $\begin{array}{c}\text { Day of } \\
\text { maximum }\end{array}$ & LRP & $\begin{array}{c}\text { Day of } \\
\text { maximum }\end{array}$ & LRP & $\begin{array}{c}\text { Day of } \\
\text { maximum }\end{array}$ & $1000 L_{3}$ & $5000 \mathrm{~L}_{3}$ & $1000 \mathrm{~L}_{3}$ & $5000 \mathrm{~L}_{3}$ \\
\hline 1 & 0.08 & 89 & 0.08 & 89 & 0.28 & 89 & 0.38 & 76 & 48 & 49 & $94 \|$ & $116 \|$ \\
\hline 2 & 0.10 & 66 & 0.23 & 35 & 0.12 & 66 & 0.26 & 41 & 75 & 79 & $91 \|$ & 84 \\
\hline 3 & 0.10 & 66 & 0.23 & 35 & 0.11 & 68 & 0.36 & 33 & 57 & 73 & $89 \|$ & 77 \\
\hline 4 & 0.10 & 67 & 0.23 & 35 & 0.11 & 68 & 0.27 & 36 & 75 & 80 & $89 \|$ & 78 \\
\hline 5 & 0.11 & 65 & 0.24 & 35 & 0.13 & 64 & 0.27 & 43 & 82 & 82 & $95 \|$ & 87 \\
\hline 6 & 0.10 & 66 & 0.23 & 35 & 0.11 & 68 & 0.25 & 33 & 75 & 80 & $89 \|$ & 74 \\
\hline 7 & 0.10 & 66 & 0.23 & 35 & 0.11 & 68 & 0.26 & 33 & 75 & 80 & $89 \|$ & 76 \\
\hline
\end{tabular}

\$ The number of days during which

challenged with 5000 larvae per d, food was predicted to increase from 0.88 to 0.9 as food CP content increased from 115 to $165 \mathrm{~g} / \mathrm{kg}$ DM. However, similar relationships between anorexia traits and $\mathrm{N}$ content of the food were not observed in lambs challenged with 1000 larvae per d, with anorexia still being present at the end of the simulation.

Effect of energy content on food intake (foods 3, 4 and 5). The effect of energy content on the food intake of uninfected lambs was large (Fig. 3(c)). This was due to the model predicting that lambs would compensate for a reduction in food energy content by increasing food intake.

For mechanism 1, the energy content of the food had little impact on the maximum extent of anorexia for both levels of parasitic challenge (Table 3); however, differences were predicted in the duration of anorexia for both levels of challenge. For lambs challenged with 1000 larvae per $d$ the duration of anorexia was predicted to increase from 57 to $82 \mathrm{~d}$ as food ME content increased from 8.75 to $11.25 \mathrm{MJ} / \mathrm{kg} \mathrm{DM}$, whilst for lambs challenged with 5000 larvae per $\mathrm{d}$ the equivalent predicted increase in the duration of anorexia was from 73 to $82 \mathrm{~d}$. Likewise, for lambs challenged with 1000 larvae per $\mathrm{d}$ the relative food intake was predicted to decrease from 0.95 to 0.93 as food ME content increased from 8.75 to $11.25 \mathrm{MJ} / \mathrm{kg}$ DM. For lambs challenged with 5000 larvae per $\mathrm{d}$ the equivalent predicted decrease in relative food intake was from 0.91 to 0.89 .

For mechanism 2, the energy content of the feed affected the maximum extent and duration of anorexia for lambs challenged with 5000 larvae per $\mathrm{d}$. The maximum extent of anorexia was predicted to be the same for foods 4 and $5(0 \cdot 27)$, whilst for food 3 the maximum extent of anorexia increased to $0 \cdot 36$. The duration of anorexia was similar ( 77 to $78 \mathrm{~d}$ ) for foods 3 and 4, whilst for food 5 the duration of anorexia increased to $87 \mathrm{~d}$. The relative food intakes of foods 3 and 5 were the same $(0 \cdot 87)$, whilst for food $4(10 \mathrm{MJ} / \mathrm{kg} \mathrm{DM})$ the relative food intake was predicted to be $0 \cdot 89$. Similar relationships were not observed in lambs challenged with 1000 larvae per d, as anorexia was still present at the end of the simulation.

Effect of varying both energy and protein content on food intake (foods 1, 4 and 7). For uninfected lambs, food intakes when offered foods 4 and 7 reflected the relative energy densities of the diets; however, bulk constraints due to the maximum capacity of the gastrointestinal tract were observed for food 1 (Fig. 3(a)).

For mechanism 1, there was little difference between the food intake characteristics of lambs offered food 4 or 7 when challenged with 1000 larvae per d, or between these foods when challenged with 5000 larvae per d. However, predicted food intake patterns differed substantially in the case of lambs offered food 1. Both larval challenge levels were predicted to result in the same maximum extent (0.08), relative food intake (0.96) and duration of anorexia ( 48 to $49 \mathrm{~d}$ ). For food 1 , the severity and extent of anorexia were less than those seen for the other foods.

For mechanism 2, lambs challenged with 5000 larvae per d and offered either food 4 or 7 had similar food intake and anorexia characteristics, as did lambs challenged with 1000 larvae per $\mathrm{d}$. However, the food intake predictions for lambs offered food 1 differed substantially, as shown in Fig. 4(d). Lambs challenged with 5000 larvae per $d$ and offered food 1 were predicted to have a maximum extent of $0 \cdot 38$, whilst lambs challenged with 1000 larvae per d were predicted to have a maximum extent of anorexia of $0 \cdot 28$. For both levels of challenge, the duration of anorexia was longer for food 1 than for all other foods, such that anorexia was still present at the end of the simulated time period. Lambs challenged with 5000 larvae per d and offered food 1 had a relative food intake of 0.73 , whilst lambs challenged with 1000 larvae per d were predicted to have a relative food intake of $0 \cdot 83$.

Effect of differing levels of parasitic challenge on anorexia. The maximum extent of anorexia for lambs given access to food 4 for increasing levels of parasite challenge is given in 


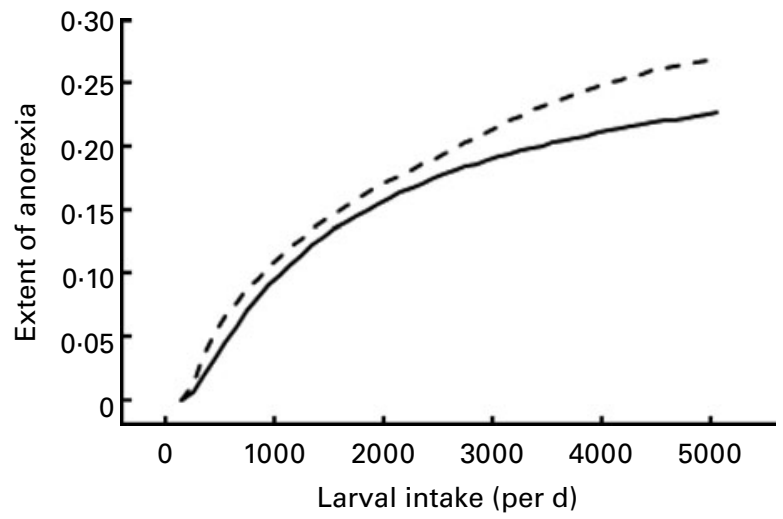

Fig. 5. Maximum extent of anorexia (i.e. the largest reduction predicted in comparison with uninfected lambs) predictions for mechanism 1 (reduction in the intrinsic capacity for growth; - ) and mechanism 2 (direct reduction in food intake; - - -) for lambs given access to food 4 (crude protein $=140 \mathrm{~g} / \mathrm{kg}$ $\mathrm{DM}$; metabolisable energy $=10 \mathrm{MJ} / \mathrm{kg} \mathrm{DM}$ ), whilst exposed to increasing levels of larval challenge.

Fig. 5, with predictions given for both mechanisms. The maximum extent of anorexia showed a non-linear increase with increasing challenge level, being on average $17 \%$ greater for mechanism 2 than mechanism 1.

\section{Daily egg counts}

The predicted daily egg counts for infected lambs for food 4 (mechanism 2) are provided in Fig. 6, as an example of the profile for all foods. Whilst total egg count was always higher for the higher challenge level, differences between foods were often small. The maximum daily egg count predicted (including day of occurrence) for mechanisms 1 and 2 for lambs offered access to all foods, whilst challenged with either 1000 or 5000 larvae per d, are summarised in Table 4.

Effect of nitrogen content on daily egg count (foods 2, 4 and 6). Results from mechanism 1 suggested that the protein content of the food would have no impact upon the maximum daily egg count predicted for either level of larval challenge. Results from mechanism 2 similarly predicted no impact on maximum daily egg count for lambs given a challenge of 1000 larvae per d. However, for the lambs challenged with 5000 larvae per $\mathrm{d}$, the protein content of the food had a small impact upon the predicted maximum daily egg count, with a $1.5 \%$ increase for food 4 and a $6 \%$ increase for food 2 in comparison with food 6.

Effect of energy content on daily egg count (foods 3, 4 and 5). For lambs challenged with 1000 larvae per d, essentially no differences were predicted in maximum daily egg count for foods 3, 4 and 5, for both mechanisms. For lambs challenged with 5000 larvae per d, mechanism 1 resulted in a 3\% increase in predicted maximum egg counts for food 5 in comparison with foods 3 and 4 . Mechanism 2 led to a 1.5\% increase for food 4 and a $15 \%$ increase for food 5 in comparison with the maximum daily egg count predicted for food 3.

Effect of varying both energy and protein content on daily egg count (foods 1, 4 and 7). For mechanism 1, no differences in maximum daily egg count were predicted for foods 4 and 7 . However, for food 1, daily egg counts were predicted to be 20 and $34 \%$ greater for lambs challenged with 1000 and 5000 larvae per d, respectively. For mechanism 2, lambs challenged with 1000 larvae per $\mathrm{d}$ were predicted to have no differences in maximum daily egg count for foods 4 and 7 and a $26 \%$ increase for food 1 in comparison with the other foods. Lambs challenged with 5000 larvae per d were predicted to have a $1.5 \%$ increase for food 4 and a $56 \%$ increase for food 1 in comparison with the maximum daily egg count predicted for food 7.

\section{Discussion}

The aim of the present paper was to investigate the consequences of two proposed mechanisms for parasite-induced anorexia on the food intake of parasitised sheep, and to explore the relationship between anorexia and food composition. In addition to exploring these results we will also compare our predictions to appropriate, published experimental data. The comparisons are qualitative as there are no experiments in the literature that have investigated the effect of food composition on the food intake of sheep infected with T. circumcincta; however, they do enable us to draw conclusions about the nature of anorexia in parasitised sheep. We conclude by proposing experiments that need to be performed in order to gain further understanding of the nature of parasite-induced anorexia and its relationship to feed composition.

\section{Accounting for the predictions made by each mechanism}

Mechanism 1. Anorexia was observed on all foods with the exception of food 1 . This was due to the energy content of the food being low, so that although lambs attempted to eat sufficient quantities of the food to meet energy requirements, they were constrained in doing so by their maximum gastrointestinal tract capacity. Whilst the desired food intake for growth was reduced due to parasitism, the maximum gastrointestinal

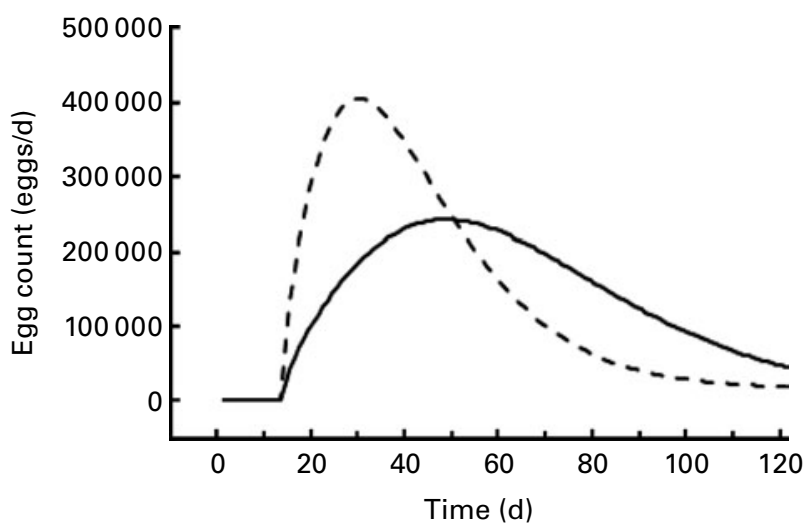

Fig. 6. Daily egg count (eggs/d) prediction for lambs given access to food 4 (crude protein $=140 \mathrm{~g} / \mathrm{kg} \mathrm{DM}$; metabolisable energy $=10 \mathrm{MJ} / \mathrm{kg} \mathrm{DM}$ ) for mechanism 2 (direct reduction in food intake), whilst exposed to either 1000 (-) or 5000 (- - -) Teladorsagia circumcincta $\mathrm{L}_{3}$ per $\mathrm{d}$. 
Table 4. Maximum daily egg count $\left(10^{-3}\right.$ eggs/d) predictions for mechanisms 1 and 2 for lambs given access to foods of different crude protein and metabolisable energy content and exposed to 1000 or 5000 Teladorsagia circumcincta $L_{3}$ per d

\begin{tabular}{|c|c|c|c|c|c|c|c|c|}
\hline \multirow[b]{3}{*}{ Food $^{*}$} & \multicolumn{4}{|c|}{ Mechanism 1† } & \multicolumn{4}{|c|}{ Mechanism 2ł } \\
\hline & \multicolumn{2}{|c|}{$1000 \mathrm{~L}_{3}$} & \multicolumn{2}{|c|}{$5000 \mathrm{~L}_{3}$} & \multicolumn{2}{|c|}{$1000 \mathrm{~L}_{3}$} & \multicolumn{2}{|c|}{$5000 \mathrm{~L}_{3}$} \\
\hline & Egg count & Day of maximum & Egg count & Day of maximum & Egg count & Day of maximum & Egg count & Day of maximum \\
\hline 1 & 292 & 55 & 534 & 33 & 305 & 59 & 624 & 39 \\
\hline 2 & 243 & 48 & 399 & 29 & 243 & 48 & 423 & 31 \\
\hline 3 & 243 & 48 & 399 & 29 & 243 & 48 & 399 & 29 \\
\hline 4 & 243 & 48 & 400 & 29 & 243 & 48 & 405 & 30 \\
\hline 5 & 246 & 49 & 411 & 30 & 247 & 49 & 458 & 32 \\
\hline 6 & 243 & 48 & 399 & 29 & 243 & 48 & 399 & 29 \\
\hline 7 & 243 & 48 & 399 & 29 & 243 & 48 & 399 & 29 \\
\hline
\end{tabular}

${ }^{*}$ For details of foods, see Table 1.

† Reduction in the intrinsic capacity for growth.

$\ddagger$ Direct reduction in food intake.

tract capacity caused a constraint greater than this and consequently anorexia was not observed. However, a $4 \%$ reduction in total food intake (Table 2) was still predicted for food 1 . This was due to the lamb being unable to compensate for nutrient loss due to parasitism because of the maximum gastrointestinal tract capacity. Therefore the implication of mechanism 1 is that the food intake of the animals will be dictated by the first operating constraint, which in this case was gut fill ${ }^{(37)}$.

For lambs challenged with 5000 larvae per $\mathrm{d}$ the maximum extent of anorexia was about 0.23 in all remaining foods, in comparison with uninfected control lambs, and for lambs challenged with 1000 larvae per $d$ the maximum extent of anorexia was about $0 \cdot 10$. The marginally increased maximum reduction in food intake and duration of anorexia predicted for food 5 is discussed below. The duration of anorexia for both levels of larval challenge was unaffected by the $\mathrm{N}$ content of the food; however, in both cases the duration of anorexia increased with the increasing energy content of the food.

The maximum daily egg count for infected lambs on all foods was the same except for foods 1 and 5. For lambs offered food 1 the increases predicted for both challenge levels arise from the maximum gastrointestinal tract capacity. Due to this, the food intake of the lambs did not meet the intake required for growth rate and the acquisition of immunity. Therefore a reduction in the rate of acquisition of immunity allowed more worms to establish, survive and produce eggs in comparison with foods 2, 3, 4, 6 and 7; subsequently the daily egg count increased. Intake of food 5 was not constrained by the maximum gastrointestinal tract capacity; nevertheless increases of 1 and $3 \%$ in the maximum daily egg count were predicted for challenge levels of 1000 and 5000 larvae per $\mathrm{d}$, respectively, in comparison with foods $2,3,4,6$ and 7. For each of these latter diets, if a lamb eats to meet its desired energy intake then it receives an excess of protein. Hence, with the reduction in the intrinsic growth rate with mechanism 1, the immune function will receive sufficient protein to achieve the optimal rate of acquisition even when anorexia is present. However, if the ME content of the food is high and the MP:ME ratio is low, as seen for food 5, a marginal deficiency in protein intake occurs in our model when anorexia is present. As a consequence, with this diet the model predicted a reduction in both growth rate and the acquisition rate of immunity (hence an increased duration of anorexia), leading to an increase in parasite burden.

Mechanism 2. Anorexia was observed for all foods at both challenge levels. For lambs given a challenge of 1000 larvae per $\mathrm{d}$ no differences were predicted in the maximum extent of anorexia for foods 3, 4, 6 and 7. The maximum extent of anorexia was largest for food 1 due to the added impact of the gut capacity, whilst foods 2 and 5 were predicted to have a small increase in comparison with foods 3, 4, 6 and 7. Similar differences were predicted for the duration of anorexia; however, further conclusions could not be drawn for this level of challenge, as anorexia was not complete by the end of the simulation.

For lambs challenged with 5000 larvae per d, the maximum extent of anorexia predicted was similar for foods 2, 4, 5, 6 and 7 , but higher for foods with low ME contents (i.e. foods 1 and 3 ). These effects are attributable to the maximum gastrointestinal capacity constraint predicted throughout the simulation for food 1 and from day 78 for food 3. The duration of anorexia generally decreased with increasing $\mathrm{N}$ content of the diet, the exception being an increase in duration for food 5, due to the impact of a low MP:ME ratio on protein intake described above. A marked increase in duration of anorexia for food 1 can be attributed to the gut fill constraint preventing food intake recovery. The maximum daily egg count predictions followed a similar pattern, with a $15 \%$ increase predicted for food 5 and a $56 \%$ increase predicted for food 1.

Summary of differences between mechanisms. The two mechanisms resulted in different predicted outcomes and implications. For mechanism 1, the energy content of the food had an impact on the duration of anorexia, and the maximum extent and duration of anorexia were affected by the combination of a high ME content and a low MP:ME ratio (food 5). Other than this, no relationships were observed between anorexia and food composition, except in the presence of the maximum gastrointestinal tract capacity (food 1). The absence of anorexia for food 1 implies that the food intake of the animal is dictated by the first operating constraint, which in this case was the gut fill. 
For mechanism 2, the $\mathrm{N}$ content of the food had an impact on the duration of anorexia, and the maximum extent and duration of anorexia were affected by the combination of a high ME content and a low MP:ME ratio (food 5). Further to this, the maximum gastrointestinal tract capacity and anorexia constraints were additive, as can be seen in the predictions for infected lambs offered access to food 1 .

\section{Comparison of predictions with experimental evidence}

Whilst experiments have been performed quantifying impacts of $T$. circumcincta infection in sheep ${ }^{(1,33)}$, the experimental data reported did not allow us to draw conclusions about the relationship between anorexia and food composition in parasitised sheep. However, data are available for Trichostrongylus colubriformis infections on a variety of different feeds. Although there are many differences between these two nematode species, for example, site of parasitism (abomasum $v$. small intestine), development rate, worm fecundity and acquisition of host immunity ${ }^{(31)}$, for purposes of comparison it is assumed that the anorexinogenic components of the immune response involved in T. colubriformis infections are similar to those for $T$. circumcincta $^{(9,17)}$, and consequently may be affected by food composition in a similar manner.

Surprisingly, there are few experiments that have investigated the effects of food energy content on the extent of anorexia; hence it is not possible to draw strong conclusions. However, the effect of protein content on the extent of anorexia has been investigated. First, Greer et al. ${ }^{(3)}$ infected immunologically naive lambs with $2000 T$. colubriformis larvae per $\mathrm{d}$ and gave them access to either a high-protein diet (energy $=10.5 \mathrm{MJ} / \mathrm{kg} \mathrm{DM} ; \quad \mathrm{CP}=175 \mathrm{~g} / \mathrm{kg} \mathrm{DM}$ ) or a lowprotein diet $($ energy $=11 \cdot 1 \mathrm{MJ} / \mathrm{kg} \mathrm{DM} ; \mathrm{CP}=93 \mathrm{~g} / \mathrm{kg} \mathrm{DM})$. The maximum daily egg count at day 42 was 400000 eggs for lambs fed the high-protein diet, and 700000 eggs for the low-protein diet. The mean reduction in food intake over the period that anorexia was observed was 0.25 and 0.15 for lambs fed the low- and high-protein food, respectively, in comparison with uninfected control lambs. To compare these results with our model predictions, we ran simulations for both anorexia mechanisms using feed descriptions, liveweight range and level of larval challenge similar to Greer et al. ${ }^{(3)}$; the only difference was that our simulations assumed T. circumcincta infections. Mechanism 1 predicted that the maximum daily egg count remained at about 289000 eggs for both the high- and low-protein food. The mean reduction in food intake over the period that anorexia was observed was 0.09 and $0 \cdot 10$ for the low- and high-protein-fed lambs, respectively, in comparison with uninfected lambs. On the other hand, mechanism 2 predicted that the maximum daily egg count was about 306000 eggs for lambs fed the low-protein food, but this decreased to about 289000 eggs for lambs fed the high-protein food. Further to this, the mean reduction in food intake over the period that anorexia was observed was predicted to be 0.12 and $0 \cdot 10$ for lambs fed the low- and high-protein food, respectively, in comparison with uninfected control lambs. In summary, Greer et al. ${ }^{(3)}$ observed that the maximum daily egg count decreased by $75 \%$, and the mean reduction in food intake also decreased, as the protein content of the food increased. For mechanism 1, the maximum daily egg count remained constant despite the change in protein content, and the mean reduction in food intake increased as the protein content of the food increased. For mechanism 2, the maximum daily egg count increased and the mean reduction in food intake decreased, as the protein content of the food increased. Due to differences in the nematode species the comparisons made here are qualitative rather than quantitative. However, whilst the changes in maximum daily egg count and food intake were smaller than those observed by Greer et $a l .{ }^{(3)}$, it was mechanism 2 that resulted in the correct predicted patterns.

Second, Kyriazakis et al. ${ }^{(38)}$ infected immunologically naive lambs with $2500 T$. colubriformis larvae per d and offered them isoenergetic foods $(10 \cdot 4 \mathrm{MJ} / \mathrm{kg} \mathrm{DM})$ that differed in $\mathrm{CP}$ content $(90,164$ or $214 \mathrm{~g} / \mathrm{kg} \mathrm{DM})$. The protein content of the food had no impact upon the extent of anorexia, with the reduction in mean food intake being $0 \cdot 10$ in comparison with uninfected lambs for all foods. Again, we simulated these experimental conditions. Mechanism 1 predicted a reduction in mean food intake of 0.07 for lambs offered the low-protein diet in comparison with uninfected lambs, and a reduction in mean food intake of 0.08 for lambs offered the medium- or high-protein diets in comparison with the controls. Mechanism 2 predicted no impact upon the extent of anorexia, with all foods showing a reduction in mean food intake of $0 \cdot 10$ in comparison with uninfected lambs, the same as that reported by Kyriazakis et al. ${ }^{(38)}$.

Last, Kyriazakis et $a l{ }^{(39)}$ infected immunologically naive lambs with $2500 \mathrm{~T}$. colubriformis larvae per d, and offered them access to isoenergetic foods (10.4 MJ/kg DM) differing in their CP content ( 86 or $206 \mathrm{~g} / \mathrm{kg} \mathrm{DM}$ ). The reduction in mean food intake was $0 \cdot 18$ and $0 \cdot 11$ for lambs offered the low- and high-protein diets, respectively, compared with uninfected lambs. For simulations carried out using the same food descriptions and level of larval challenge, over the same time period, mechanism 1 predicted a reduction in mean food intake of 0.11 and 0.12 for lambs offered the low- and high-protein foods, respectively, in comparison with uninfected lambs. With mechanism 2 , reductions in mean food intake were predicted to be $0 \cdot 14$ and $0 \cdot 10$ for lambs offered the low- and high-protein diets, respectively, showing a similar trend to that reported by Kyriazakis et al. ${ }^{(39)}$. Thus, in all three cases investigated it was mechanism 2 that led to more accurate representations of the trends observed in the experimental data, predicting a relationship between food composition and the extent of anorexia, with impacts on daily egg counts.

\section{Interpretation and implications of model predictions}

In terms of the duration of anorexia, there is convincing evidence that food composition has an impact, with duration being reduced on high-quality foods ${ }^{(39-41)}$. This relationship between food composition and the duration of anorexia has been suggested to be due to food composition affecting the degree of expression of immunity in pathogen-challenged hosts $^{(31)}$, subsequently leading to the observed effect on the 
duration of anorexia via an impact upon immunity and parasite burden. Thus, animals on poor-quality diets (for example, foods of low protein and energy content) may be expected to suffer proportionally more the consequences of infection than animals on good-quality diets (for example, foods of high protein and energy content) ${ }^{(31)}$. Unfortunately, mechanism 1 predicted the opposite of this, with the duration of anorexia tending to increase as the energy content of the food increased.

There is also evidence that the protein content of the feed affects the daily egg count, with lambs offered lower-protein feeds having a higher daily egg count than lambs offered a higher-protein feed ${ }^{(3)}$. This provides further support to the finding that food composition affects the degree of expression of immunity, with a consequent relationship between food composition and duration of anorexia as suggested above. Once again, these findings are consistent with mechanism 2 in which food composition affected daily egg counts and the duration of anorexia.

Unfortunately, no comparable experimental data could be found for infected lambs on diets of sufficiently low energy content to incur the maximum gastrointestinal tract capacity constraint. In studies that have used foods of sufficiently low quality to cause this constraint, for example, Anindo et al. ${ }^{(42)}$, insufficient detail has been given on food composition and there have been no uninfected control groups. This lack of data may reflect the view and practice that parasitised lambs need to be fed better-quality feeds; whilst this may be a fair conclusion, it may not always be possible in practice.

Although mechanism 2 has been more consistent with the experimental data, the lack of comparable experimental data for foods that impose the maximum gastrointestinal tract capacity constraint does not allow us to draw conclusions on the additivity of signals involved in the regulation of food intake. Mechanism 1 implies that food intake would be determined by the most limiting constraint. It has previously been suggested that the processes regulating appetite are disrupted by cytokine release that accompanies infection ${ }^{(10,11)}$, and thus there is a redundancy of the signals operating to regulate food intake ${ }^{(37)}$. On the other hand, mechanism 2 implies that there is an additivity in the effects of the signals that control voluntary food intake. It has previously been proposed that various satiety signals act additively to control voluntary food intake ${ }^{(43,44)}$. Thus both mechanisms present viable approaches to describing the regulation of voluntary food intake, but conclusions cannot be drawn on this topic until the relevant experiments have been carried out.

Further experimental research would help determine the relationship between food composition and parasite-induced anorexia. Whilst several experiments have systematically investigated the effects of food protein content on the extent of anorexia and the impacts of parasitism, further experiments are required to investigate the impacts of food energy and protein content, separately and in conjunction. It would be of particular interest to perform these challenge experiments using T. circumcintca, both to obtain de novo data for sheep infected by this parasite and to provide data that may be compared with those obtained from sheep challenged with
T. colubriformis. It would also be of interest to obtain data for foods of sufficiently low energy content as to impose the maximum gastrointestinal tract capacity constraint. This would enable us to determine whether the factors that regulate voluntary food intake act additively, and whether low larval challenges are sufficient to cause anorexia for lowquality foods.

In summary, it would be of great biological interest to better understand the causes and consequences of anorexia. The suggested experiments coupled with predictive models may allow us to achieve this.

\section{Conclusion}

The mechanism by which anorexia is modelled leads to different predicted outcomes from infection. Mechanism 1, reduced intrinsic growth with consequent reductions in food intake, led to predictions that the duration of anorexia increases with increasing energy content of the food, and that food intake is determined by the first operating constraint (maximum gastrointestinal tract capacity). Mechanism 2, a direct reduction in food intake, led to predictions that the duration of anorexia decreases with increasing protein content of the food, and that impacts of anorexia and the maximum gastrointestinal tract capacity upon voluntary food intake are possibly additive. Mechanism 2 was more consistent with the theories and experimental data presented for a wide range of food qualities.

\section{Acknowledgements}

Y. C. S. M. L. was funded by a Biotechnology and Biological Sciences Research Council (BBSRC) CASE studentship in conjunction with Merial. We would also like to acknowledge further financial support from Biosciences Knowledge Transfer Network (Biosciences KTN). We are grateful to Dr Andy Forbes of Merial for the support and encouragement provided to us throughout the course of this project, and Dr Andrea DoeschlWilson for helpful comments on the manuscript. The contribution from S. C. B. was funded by a BBSRC Institute Strategic Programme Grant. All three authors have contributed equally to the model construction, design and conduct of the experiments, and interpretation of the outcomes.

The authors declare no conflicts of interest.

\section{References}

1. Coop RL, Sykes AR \& Angus KW (1982) The effect of three levels of intake of Ostertagia circumcincta larvae on growth rate, feed intake and body composition of growing lambs. J Agric Sci 98, 247-255.

2. Sandberg FB, Emmans GC \& Kyriazakis I (2006) A model for predicting feed intake of growing animals during exposure to pathogens. J Anim Sci 84, 1552-1566.

3. Greer AW, Sedcole RJ, Jay NP, et al. (2009) Protein supply influences the nutritional penalty associated with the development of immunity in lambs infected with Trichostrongylus colubriformis. Animal 3, 437-445. 
4. Reid JFS, Armour J, Urquhart GM, et al. (1970) Studies on ovine fascioliasis 1 . Observations on the sequential development of the naturally-acquired disease. Vet $\operatorname{Rec} \mathbf{8 6}, 242-249$.

5. Horak IG (1970) Paramphistomiasis of domestic ruminants. Adv Parasitol 9, 33-72.

6. Saad AM, Hussein MF, Dargie JD, et al. (1984) The pathogenesis of experimental Schistosoma bovis infections in Sudanese sheep and goats. J Comp Pathol 94, 371-385.

7. Sykes AR \& Kyriazakis I (2007) Opportunities to control herbivore nematodes through manipulation of the grazing environment. In Proceedings of the 7 th International Symposium on the Nutrition of Herbivores, Beijing, China, pp. 329-353 [QX Meng, LP Ren and ZJ Cao, editors]. Beijing: China Agricultural University Press.

8. Nieuwhof GJ \& Bishop SC (2005) Costs of the major endemic diseases of sheep in Great Britain and the potential benefits of reduction in disease impact. Anim Sci 81, 23-29.

9. Kyriazakis I, Tolkamp BJ \& Hutchings MR (1998) Towards a functional explanation for the occurrence of anorexia during parasitic infections. Anim Behav 56, 265-274.

10. Langhans W (2000) Anorexia of infection: concurrent prospects. Nutrition 16, 996-1005.

11. Plata-Salamán CR (2001) Cytokines and feeding. Int J Obes Relat Metab Disord 25, S24-S52.

12. Wellock IJ, Emmans GC \& Kyriazakis I (2003) Modelling the effects of thermal environment and dietary composition of pig performance: model logic and concepts. Anim Sci $\mathbf{7 7}$, $255-266$

13. Vagenas D, Bishop SC \& Kyriazakis I (2007) A model to account for the consequences of host nutrition on the outcome of gastrointestinal parasitism in sheep: logic and concepts. Parasitology 134, 1263-1277.

14. Vagenas D, Bishop SC \& Kyriazakis I (2007) A model to account for the consequences of host nutrition on the outcome of gastrointestinal parasitism in sheep: model evaluation. Parasitology 134, 1279-1289.

15. Burdge GC, Hanson MA, Slater-Jefferies JL, et al. (2007) Epigenetic regulation of transcription: a mechanism for inducing variations in phenotype (fetal programming) by differences in nutrition during early life? Br J Nutr 97, 1036-1046.

16. Black JL, Bray HJ \& Giles LR (1999) The thermal and infectious environment. In A Quantitative Biology of the Pig, pp. 71-97 [I Kyriazakis, editor]. Wallingford, UK: CAB International.

17. Kyriazakis I (2010) Is anorexia during infections in animals affected by food composition? Anim Feed Sci Technol 156, $1-9$.

18. Stear MJ, Doligalska M \& Donskow-Schmelter K (2007) Alternatives to anthelmintics for the control of nematodes in livestock. Parasitology 134, 139-151.

19. Wellock IJ, Emmans GC \& Kyriazakis I (2004) Describing and predicting potential growth in the pig. Anim Sci $\mathbf{7 8}$, 379-388.

20. Agricultural and Food Research Council (1993) Energy and Protein Requirements of Ruminants. An Advisory Manual Prepared by AFRC Technical Committee on Responses to Nutrients. Wallingford, UK: CAB International.

21. Emmans GC (1994) Effective energy: a concept of energyutilization applied across species. Br J Nutr 71, 801-821.

22. Kyriazakis I \& Emmans GC (1995) The voluntary feed-intake of pigs given feeds based on wheat bran, dried citrus pulp and grass meal, in relation to measurements of feed bulk. Br J Nutr 73, 191-207.

23. Lewis RM, Macfarlane JM, Simm G, et al. (2004) Effects of food quality on growth and carcass composition in lambs of two breeds and their cross. Anim Sci 78, 355-367.
24. Houdijk JM, Jessop NS \& Kyriazakis I (2001) Nutrient partitioning between reproductive and immune functions in animals. Proc Nutr Soc 60, 515-525.

25. Sykes AR (2000) Environmental effects on animal production: the nutritional demands of nematode parasite exposure in sheep. Asian Austral J Anim 13, 343-350.

26. Bishop SC \& Stear MJ (1997) Modelling responses to selection for resistance to gastro-intestinal parasites in sheep. Anim Sci 64, 469-478.

27. Stear MJ \& Bishop SC (1999) The curvilinear relationship between worm length and fecundity of Ostertagia circumcincta. Int J Parasitol 29, 777-780.

28. Louie K, Vlassoff A \& Mackay A (2005) Nematode parasites of sheep: extension of a simple model to include host variability. Parasitology 130, 437-446.

29. Jackson F, Greer AW, Huntley J, et al. (2004) Studies using Teladorsagia circumcincta in an in vitro direct challenge method using abomasal tissue explants. Vet Parasitol 124, 73-89.

30. Kao RR, Leathwick DM, Roberts MG, et al. (2000) Nematode parasites of sheep: a survey of epidemiological parameters and their application in a simple model. Parasitology 121, 85-103.

31. Coop RL \& Kyriazakis I (1999) Nutrition-parasite interaction. Vet Parasitol 84, 187-204.

32. Greer AW, Huntley JF, Mackellar A, et al (2008) The effect of corticosteroid treatment on local immune responses, intake and performance in lambs infected with Teladorsagia circumcincta. Int J Parasitol 38, 1717-1728.

33. Coop RL, Graham RB, Jackson F, et al. (1985) Effect of experimental Ostertagia circumcincta infection on the performance of grazing lambs. Res Vet Sci 38, 282-287.

34. Valderrábano J, Delfa R \& Uriarte J (2002) Effect of level of feed intake on the development of gastrointestinal parasitism in growing lambs. Vet Parasitol 104, 327-338.

35. Doeschl-Wilson AB, Vagenas D, Kyriazakis I, et al. (2008) Exploring the assumptions underlying genetic variation in host nematode resistance. Genet Sel Evol 40, 241-264.

36. Noci F, Monahan FJ, French P, et al. (2005) The fatty acid composition of muscle fat and subcutaneous adipose tissue of pasture-fed beef heifers: influence of the duration of grazing. J Anim Sci 83, 1167-1178.

37. Kyriazakis I (2003) The control and prediction of food intake in sickness and in health. In Perspectives in Pig Science, pp. 381-403 [J Wiseman, M Varley and B Kemp, editors]. Nottingham, UK: Nottingham University Press.

38. Kyriazakis I, Oldham JD, Coop RL, et al. (1994) The effect of subclinical intestinal nematode infection on the diet selection of growing sheep. Br J Nutr 72, 665-677.

39. Kyriazakis I, Anderson DH, Oldham JD, et al. (1996) Longterm subclinical infection with Trichostrongylus colubriformis: effects on feed intake, diet selection and performance of growing lambs. Vet Parasitol 61, 297-313.

40. Datta FU, Nolan JV, Rowe JB, et al. (1998) Protein supplementation improves the performance of parasitized sheep fed a straw-based diet. Int J Parasitol 28, 1269-1278.

41. Knox MR \& Steel JW (1999) The effects of urea supplementation on production and parasitological responses of sheep infected with Haemonchus contortus and Trichostrongylus colubriformis. Vet Parasitol 83, 123-135.

42. Anindo D, Toé F, Tembely S, et al. (1998) Effect of molassesurea-block (MUB) on dry matter intake, growth, reproductive performance and control of gastrointestinal nematode infection of grazing Menz ram lambs. Small Rumin Res 27, 63-71.

43. Forbes JM (1986) The Voluntary Food Intake of Farm Animals. London: Butterworth. 
44. Anil MH, Mbanya JN, Symonds HW, et al. (1993) Responses in the voluntary intake of hay or silage by lactating cows to intraruminal infusions of sodium acetate or sodium propionate, the tonicity of rumen fluid or rumen distension. Br J Nutr 69, 699-712.

45. Emmans GC (1997) A method to predict the food intake of domestic animals from birth to maturity as a function of time. J Theor Biol 186, 189-200.

46. Emmans GC \& Kyriazakis I (1999) Growth and body composition. In A Quantitative Biology of the Pig, pp. 181-197 [I Kyriazakis, editor]. Wallingford, UK: CAB International.

47. Emmans GC \& Kyriazakis I (1997) Models of pig growth: problems and proposed solutions. Livest Prod Sci 51, 119-129.

48. Emmans GC \& Fisher C (1986) Problems of nutritional theory. In Nutritional Requirements and Nutritional Theory, pp. 9-57 [C Fisher and KN Boorman, editors]. London: Butterworths.

49. Cronje PB \& Smuts M (1994) Nutrient partitioning in merino rams with different wool growth-rates. Anim Prod 59, $55-60$.

50. Coffey MP, Emmans GC \& Brotherstone S (2001) Genetic evaluation of dairy bulls for energy balance traits using random regression. Anim Sci 73, 29-40.

51. Yin XY, Goudriaan J, Lantinga EA, et al. (2003) A flexible sigmoid function of determinate growth. Ann Bot-London 91, 361-371.

52. Steel JW, Symons LEA \& Jones WO (1980) Effects of level of larval intake on the productivity and physiological and metabolic responses of lambs infected with Trichostrongylus colubriformis. Aust J Agr Res 31, 821-838.

\section{Appendix 1}

\section{Intrinsic growth model}

Growth was assumed to follow a Gompertz growth curve trajectory. The intrinsic growth rate of the lamb $(B ; \mathrm{kg} / \mathrm{d})^{(45)}$ is estimated as:

$$
B=\frac{0 \cdot 023}{P_{m}^{0 \cdot 27}},
$$

where $P_{m}=$ body protein content at maturity (kg).

The expected (maximum) daily body protein growth $\left(\Delta P G_{\max }\right)^{(45)}$ is estimated as:

$$
\Delta P G_{\max }=P \cdot B \cdot \ln \left(\frac{P_{m}}{P}\right)(\mathrm{kg} / \mathrm{d}),
$$

where $P=$ current body protein mass $(\mathrm{kg})$.

The desired lipid growth $\left(\Delta L_{\mathrm{des}}\right)^{(46)}$ is estimated as:

$$
\Delta L_{\mathrm{des}}=\Delta P G_{\max } \cdot\left(\frac{L_{m}}{P_{m}}\right) \cdot d \cdot\left(\frac{P}{P_{m}}\right)^{(d-1)}(\mathrm{kg} / \mathrm{d}),
$$

where $L_{m}=$ body lipid content at maturity (kg), and $d=1 \cdot 46 \cdot\left(\frac{L_{m}}{P_{m}}\right)^{0 \cdot 23}(45)$.

The daily accretion of ash $(\Delta A s h)^{(47,48)}$ is estimated as:

$$
\Delta A s h=0 \cdot 211 \Delta P G(\mathrm{~kg} / \mathrm{d}),
$$

where $\triangle P G=$ protein growth $(\mathrm{kg})$
The daily accretion of water $(\Delta \text { Water })^{(47,48)}$ is estimated as:

$$
\Delta \text { Water }=2 \cdot 65 \Delta P G\left(\frac{P}{P_{m}}\right)^{-0.185}(\mathrm{~kg} / \mathrm{d}) .
$$

The expected maximum daily wool growth $\left(\Delta P W_{0 o l} l_{\max }\right)^{(49)}$ is estimated as:

$$
\Delta P \text { Wool }_{\max }=\left(\frac{0 \cdot 0009 \cdot P}{P_{m}^{0 \cdot 27}}\right)+\left(0 \cdot 16 \cdot \Delta P G_{\max }\right)(\mathrm{kg} / \mathrm{d}) .
$$

Gut fill $(G F)$ depends on the properties of the food that the sheep has access to, mainly energy content, and is estimated according to Coffey et al. ${ }^{(50)}$ as:

$$
G F=F I \cdot\left(11-\left(\frac{7 \cdot M E}{15}\right)\right)(\mathrm{kg} / \mathrm{d})
$$

where $F I=$ food intake $(\mathrm{kg} \mathrm{DM})$ and $M E=$ metabolised energy of the feed (MJ/kg DM).

\section{Resource requirements and food intake}

The protein required for maintenance $\left(P R_{\text {maint }}\right)^{(12)}$ is estimated as:

$$
P R_{\text {maint }}=0 \cdot 004 \cdot\left(\frac{P}{P_{m}^{0 \cdot 27}}\right)(\mathrm{kg} / \mathrm{d}) .
$$

The protein required for growth $\left(P R_{\text {Growth }}\right)^{(12)}$ is estimated as:

$$
P R_{\text {Growth }}=\frac{\Delta P G_{\max }}{e p}(\mathrm{~kg} / \mathrm{d})
$$

where $e P=$ efficiency of protein deposition $(0 \cdot 26)^{(20)}$.

The protein required for wool $\left(P R_{\mathrm{Wool}}\right)^{(13)}$ is estimated as:

$$
P R_{\mathrm{Wool}}=\frac{\Delta P W o o l_{\text {max }}}{e w}(\mathrm{~kg} / \mathrm{d}),
$$

where $e w=$ efficiency of protein use for wool $(0 \cdot 59)^{(20)}$.

The energy required for maintenance $\left(E R_{\text {maint }}\right)^{(48)}$ is estimated as:

$$
E R_{\text {maint }}=1 \cdot 63 \cdot\left(\frac{P}{P_{m}^{0 \cdot 27}}\right)(\mathrm{kg} / \mathrm{d}) .
$$

The energy required for growth $\left(E R_{\mathrm{Growth}}\right)^{(12)}$ is estimated as:

$$
E R_{\text {Growth }}=\left(b l \cdot \Delta L_{\mathrm{des}}\right)+\left(b p \cdot \Delta P G_{\max }\right)(\mathrm{kg} / \mathrm{d}),
$$

where $b l=$ energetic cost per $\mathrm{kg}$ of lipid deposition $(56 \mathrm{MJ} /$ $\mathrm{kg})^{(21)}$ and $b p=$ energetic cost per $\mathrm{kg}$ of protein deposition $(50 \mathrm{MJ} / \mathrm{kg})^{(21)}$.

The energy required for wool $\left(E R_{\text {Wool }}\right)^{(13)}$ is estimated as:

$$
E R_{\text {Wool }}=b p \cdot \Delta P W o o l_{\max }(\mathrm{kg} / \mathrm{d}) .
$$

The desired food intake for meeting the energy requirements of the lamb $\left(F I_{\mathrm{E}}\right)$ is estimated as:

$$
F I_{\mathrm{E}}=\frac{E R}{E E C}(\mathrm{~kg} \mathrm{DM} / \mathrm{d}),
$$

where $E E C=$ effective energy content ${ }^{(21)}$. 
The desired food intake for meeting the protein requirements of the lamb $\left(F I_{\mathrm{P}}\right)$ is estimated as:

$$
F I_{\mathrm{P}}=\frac{P R}{M P}(\mathrm{~kg} \mathrm{DM} / \mathrm{d})
$$

where $M P=$ feed metabolisable protein content ${ }^{(20)}$.

The relationship between effective energy $(E E ; \mathrm{MJ} / \mathrm{kg})$ and metabolisable energy $(M E ; \mathrm{MJ} / \mathrm{kg})$ is given as:

$$
E E=1.15 M E-3.84-4.67 D C P(\mathrm{MJ} / \mathrm{kg} \text { organic matter }),
$$

where $D C P=$ digestible crude protein, $D C P=0.9 C P-0.032$ $(\mathrm{g} / \mathrm{kg} \mathrm{DM})^{(21)}$.

\section{Constrained resources}

Constrained food intake $(C F I)$ is defined as ${ }^{(23)}$ :

$$
C F I=\frac{C A P}{0.93-\left(\frac{M E}{15.58}\right)}(\mathrm{kg} / \mathrm{d}),
$$

where $C A P=$ capacity of the animal for daily indigestible organic matter $(\mathrm{kg})$ and $M E=$ metabolisable energy content of the feed (MJ/kg DM).

The capacity of the animal for daily indigestible organic matter $(C A P ; \mathrm{kg})^{(23)}$ is estimated as the smaller of:

$$
\begin{aligned}
& C A P=0 \cdot 0223 \cdot B W \\
& \text { or }: C A P=0 \cdot 0223 \cdot 0 \cdot 51 \cdot B W_{\mathrm{m}}(\mathrm{kg} / \mathrm{d}),
\end{aligned}
$$

where $B W=$ current body weight of the lamb $(\mathrm{kg})$ and $B W_{\mathrm{m}}=$ body weight of the lamb at maturity $(\mathrm{kg})$.

\section{Allocation of nutrients}

The daily lipid deposited $(\Delta \text { Lipid })^{(13)}$ is:

$$
\Delta \text { Lipid }=\frac{\left((F I \cdot E E C)-E_{\text {maint }}-E_{\text {Protein }}\right)}{b l}(\mathrm{~kg} / \mathrm{d}),
$$

where $E_{\text {maint }}=$ energy for maintenance $(\mathrm{MJ} / \mathrm{d}), E_{\text {Protein }}=$ energy for protein and $E_{\text {Protein }}=b p \cdot \Delta P G_{\max }(\mathrm{MJ} / \mathrm{d})$.

If $\Delta$ Lipid is negative, then lipid will be catabolised to satisfy the animal's energetic needs for other functions as follows:

$$
\Delta \text { Lipid }=\frac{\left(\left(F I \cdot E E C-E_{\text {Maint }}-E_{\text {Protein }}\right)\right)}{b l_{\mathrm{C}}}(\mathrm{kg} / \mathrm{d}),
$$

where $b l_{\mathrm{C}}=$ heat combustion of lipid $(39 \mathrm{MJ} / \mathrm{kg})^{(20)}$.

Labile protein $\left(P_{\text {Labile }}\right)^{(24,25)}$ is defined by:

$$
P_{\text {Labile }}=0 \cdot 2 \cdot P_{\max }(\mathrm{kg}),
$$

where $P_{\max }=$ maximum achieved body protein content $(\mathrm{kg})$.

The baseline body lipid level $\left(L_{\text {base }}\right)^{(13)}$ is estimated as:

$$
L_{\text {base }}=0 \cdot 2 \cdot P(\mathrm{~kg}) \text {. }
$$

\section{Protein loss}

The potential protein loss $\left(P L I_{\text {Pot }}\right)$ due to larval intake $(L I)$ when there is no immune response is given by the following exponential relationship ${ }^{(51)}$ :

$$
\begin{gathered}
P L I_{\text {Pot }}=P L O S S_{\max } \cdot\left(1+\frac{L I_{\max }-L I}{L I_{\max }-L I_{\text {infl }}}\right) . \\
\left(\frac{L I}{L I_{\max }}\right)^{\left(\frac{L I_{\max }}{L I_{\max }-L_{\text {infl }}}\right)}(\mathrm{kg} / \mathrm{d}),
\end{gathered}
$$

where $P L O S S_{\max }=$ daily protein loss when $L I$ equals $L I_{\max }$ $\left(0.01 \mathrm{~kg} / \mathrm{d}^{(52)}\right), L I_{\text {infl }}=$ inflection point of the relationship between $P L I_{\text {Pot }}$ and $L I$ (5000 larvae per $\left.\mathrm{d}^{(13,14)}\right)$ and $L I_{\max }=$ maximum of the relationship between $L I$ and $P L I_{\text {Pot }}(10000$ larvae per $\mathrm{d}^{(52)}$ ).

Protein loss due to larval intake $(P L I)^{(13)}$ is then given as:

$$
P L I=P L I_{\mathrm{Pot}} \cdot\left(\frac{P L I_{\mathrm{Pot}} \cdot e^{-K_{\mathrm{Imm}} \cdot P R Q_{\mathrm{Imm}}}}{\text { PLOSS }_{\max }}\right)^{\left(\frac{P A C_{\mathrm{Imm}}}{\left(P A C_{\mathrm{Imm}}\right)_{\max }}\right)}(\mathrm{kg} / \mathrm{d}),
$$

where $P R Q_{\text {Imm }}=$ protein required for immunity, $P A C_{\mathrm{Imm}}=$ protein allocated daily to immunity $(\mathrm{kg} / \mathrm{d})$ and $\left(P A C_{\mathrm{Imm}}\right)_{\max }=$ maximum protein allocated to immunity $\left(0 \cdot 2 \times P_{\text {maint }}(\mathrm{kg} /\right.$ d) $\left.{ }^{(24)}\right)$ and $K_{\text {Imm }}=$ exponent associated with $P A C_{\text {Imm }}$ (equation 25).

The exponent associated with $P A C_{\mathrm{Imm}}\left(K_{\mathrm{Imm}}\right)^{(13)}$ is given as:

$$
K_{\mathrm{Imm}}=-\frac{\ln \left(\frac{\text { PLoss }_{\min }}{\text { PLos }_{\max }}\right)}{\left(P A C_{\mathrm{Imm}}\right)_{\max }},
$$

where PLoss $_{\min }=$ value at which the animal stops allocating protein to immunity $\left(0 \cdot 0001^{(13,14)}\right)$.

Fecundity was scaled $\left(F_{\text {Scaled }}\right)^{(26)}$ such that it declined with increasing worm mass:

$$
F_{\text {Scaled }}=F \cdot\left(\frac{W B}{2500}\right)^{-0.25} .
$$

Worm mass $(W M)^{(13)}$ is estimated as:

$$
W M=W B \cdot F_{\text {Scaled }} .
$$

The protein loss caused by worm mass $(P W M)$ is given by the following exponential relationship ${ }^{(13)}$ :

$$
\begin{gathered}
P W M=P L O S S_{\max } \cdot\left(1+\frac{L I_{\max }-(0 \cdot 8 \cdot W M)}{L I_{\max }-L I_{\text {infl }}}\right) . \\
\left(\frac{0 \cdot 8 \cdot W M}{L I_{\max }}\right)^{\left(\frac{L_{\max }}{I I_{\max }-I_{\text {infl }}}\right)}(\mathrm{kg} / \mathrm{d}) .
\end{gathered}
$$

\section{Immune response}

The protein required for immunity for larval intake $\left(P R Q_{\text {LI_Imm }}\right)^{(13)}$ is estimated as:

$$
P R Q_{\mathrm{LI} \_\mathrm{Imm}}=\left(P A C_{\mathrm{Imm}}\right)_{\max } \cdot \frac{\ln \left(\frac{\text { PLoss }_{\min }}{\text { PLI }_{\mathrm{pot}}}\right)}{\ln \left(\frac{\text { Loss }_{\min }}{\text { PLos }_{\max }}\right)}(\mathrm{kg} / \mathrm{d}),
$$

where PLoss $_{\min }=$ minimum damage for which there is no immune response $\left(0 \cdot 0001^{(13,14)}\right)$. 
The protein required for immunity for worm mass $\left(P R Q_{\text {WM_Imm }}\right)^{(13)}$ is estimated as:

$$
P R Q_{\text {WM_Imm }}=-\frac{\ln \left(\frac{\text { PLoss }_{\mathrm{min}}}{P W M}\right)}{-K_{\mathrm{Imm}}}(\mathrm{kg} / \mathrm{d}) .
$$

\section{Effect of parasitism on protein partitioning}

The proportion of protein allocated to production $\left(\mathrm{PAC}_{\text {Growth }}\right)^{(13)}$ is given as:

$$
P A C_{\text {Growth }}=\frac{P R}{P R+\left(P R Q_{\mathrm{Imm}}\right)_{\mathrm{Tot}}}(\mathrm{kg} / \mathrm{d}) .
$$

The proportion of protein allocated to immunity $\left(\mathrm{PAC}_{\mathrm{Imm}}\right)^{(13)}$ is given as:

$$
P A C_{\mathrm{Imm}}=\frac{\left(P R Q_{\mathrm{Imm}}\right)_{\mathrm{Tot}}}{P R+\left(P R Q_{\mathrm{Imm}}\right)_{\mathrm{Tot}}}(\mathrm{kg} / \mathrm{d}) .
$$

Protein associated with the immune function $\left(P_{\mathrm{Imm}}\right)^{(13)}$ is estimated as:

$$
P_{\mathrm{Imm}}=0 \cdot 59 \cdot P A C_{\operatorname{Imm}}(\mathrm{kg} / \mathrm{d}) .
$$

